

\title{
Spontaneous recovery of functional diversity and rarity of ground-living spiders shed light on the conservation importance of recent woodlands
}

\author{
Loïs Morel, B. Dujol, C. Courtial, M. Vasseur, B. Leroy, F. Ysnel
}

\section{- To cite this version:}

Loïs Morel, B. Dujol, C. Courtial, M. Vasseur, B. Leroy, et al.. Spontaneous recovery of functional diversity and rarity of ground-living spiders shed light on the conservation importance of recent woodlands. Biodiversity and Conservation, 2019, 28 (3), pp.687. 10.1007/s10531-018-01687-3 . hal02043736

HAL Id: hal-02043736

https://hal-univ-rennes1.archives-ouvertes.fr/hal-02043736

Submitted on 25 Mar 2019

HAL is a multi-disciplinary open access archive for the deposit and dissemination of scientific research documents, whether they are published or not. The documents may come from teaching and research institutions in France or abroad, or from public or private research centers.
L'archive ouverte pluridisciplinaire HAL, est destinée au dépôt et à la diffusion de documents scientifiques de niveau recherche, publiés ou non, émanant des établissements d'enseignement et de recherche français ou étrangers, des laboratoires publics ou privés. 
1 Spontaneous recovery of functional diversity and rarity of ground-living

2 spiders shed light on the conservation importance of recent woodlands

3

4 Loïs Morel $^{1 *}$, Benoît Dujol ${ }^{1}$, Cyril Courtial ${ }^{1}$, Manon Vasseur ${ }^{1}$, Boris Leroy ${ }^{2}$ and Frédéric 5 Ysnel $^{1}$

$6 \quad{ }^{1}$ Géoarchitecture, Territoires, Urbanisation, Biodiversité et Environnement (EA 7462

7 Géoarchitecture-TUBE) Université de Rennes 1, Université de Brest, Campus de Beaulieu, 835042 Rennes, France.

$9 \quad{ }^{2}$ Unité Biologie des Organismes et Écosystèmes Aquatiques (UMR 7208 BOREA), Sorbonne

Universités, Muséum National d'Histoire Naturelle, Université de Caen Normandie, Université des Antilles, CNRS, IRD, 43 Rue Cuvier, CP26, 75005 Paris, France, boris.leroy@mnhn.fr

* Corresponding author: Loïs MOREL, Université de Rennes 1, Campus de Beaulieu, Bâtiment 25, $1^{\mathrm{er}}$ étage, 35042 Rennes cedex, E-mail: morellois@hotmail.com Tel : +33(0)6 88570676 
Page $\mathbf{2}$ on $\mathbf{5 1}$

\section{Abstract}

Secondary (or recent) woodlands, whose development is favoured by massive farmland abandonment, are increasingly seen as promising habitats that limit losses of biodiversity and ecosystem processes. The importance of temporal forest continuity (i.e. the duration of an uninterrupted forest state) for conservation of the forest fauna has been demonstrated for several taxa, but its influence on functional diversity and conservation importance of communities remains unclear. We studied how temporal continuity can shape taxonomic and functional composition and structure of forest-ground spider communities at a regional scale. According to broad-scale ecological site characteristics, species composition and - to a lesser extent - trait distribution substantially diverged between ancient and recent forest sites. Yet, we found hardly any significant differences in functional $\beta$-diversity, community structure, or conservation importance between the two forest categories. The only difference was for functional originality, which quantifies the average functional uniqueness of species within an assemblage: spiders' communities of the ancient forests was more functionally original than those of the recent woodlands. Thus, in a conservation perspective, our study provides evidence that each forest harbours original species combinations, suggesting that each of them is irreplaceable, especially for ancient forests, which are functionally more original; however, recent woodlands have a high potential to spontaneously recover typical forest fauna communities with very similar structural and functional profiles to those of ancient forests.

\section{Keywords}

Arthropods; Farmland abandonment; Land use changes; Rewilding; Feral woodlands 
Page $\mathbf{3}$ on $\mathbf{5 1}$

\section{Introduction}

Land use change is considered as one of the major drivers of biodiversity changes in the terrestrial biosphere (Newbold et al. 2015). It can result in loss of both local and regional biodiversity (Sala 2000) or represent an opportunity for biological conservation through spontaneous rewilding (Pereira and Navarro 2015). Beyond modifications of species composition and structure of assemblages, these changes may affect ecosystem functioning (e.g. productivity, material cycling or resilience) by driving shifts of functional features of communities; e.g. by favouring the development of fast-growing plant species and thereby increasing ecosystem productivity (Allan et al. 2015). As a consequence, biodiversity conservation and related ecosystem processes are highly dependent on our understanding of the way historical and present land uses shape ecological communities. This is especially the case of mature ecosystems such as forest environments, which harbour high levels of biodiversity and numerous specialist species.

For centuries, regional species pools of woodlands have continuously been reshaped by successive periods of deforestation and reforestation (Kirby and Watkins 2015). These oscillations of the forest cover have brought about a profound dichotomy in forest landscapes, with coexistence of ancient forests and recent woodlands. In Western Europe, this trend increased in the last decades following massive abandonment of agricultural land resulting from socio-economical changes in developed countries (Renwick et al. 2013). Ancient forests are defined by the absence of a historical record of agricultural land use (and not as the absence of management) and have been continuously wooded for centuries (Hermy et al. 1999). Recent woodlands result from spontaneous processes of ecosystem de-domestication (Hermy and Verheyen 2007); they have been described as "feral" and are considered as novel ecosystems by several authors (Hobbs et al. 2013). This categorisation is not established yet (Miller and Bestelmeyer 2016; Murcia et al. 2014); it mainly relies on the importance of land- 
use legacies (e.g. soil condition) that can lead to major differences in community composition and diversity between ancient and recent forests (see reviews by Hermy and Verheyen 2007; Spake et al. 2015).

In recent decades, there has been a growing effort to improve our understanding of forest fauna - including invertebrate taxa - responses to farmland abandonment (Bowen et al. 2007; Spake et al. 2015). In Europe, the key role of ancient forests for the conservation of arthropod communities has been demonstrated for carabid beetles (Assmann 1999; Desender et al. 1999; Goßner et al. 2008), saproxylic weevils (Buse 2011) and millipedes (Magura et al. 2015). Thus, although significant recovery of entomofauna has been noted in secondary woodlands (Queiroz et al. 2014), temporal forest continuity admittedly strongly influences species composition and richness of certain taxonomic groups through dispersal and recruitment limitations (Bowen et al. 2007; Spake et al. 2015).

Beyond these taxonomic differences, the functional responses of arthropod communities to forest continuity are still poorly understood when trying to determine whether recent woodlands can play a significant role in recovering biodiversity losses. Yet, by accounting for ecological differences among species, functional diversity may improve our understanding of ecosystem processes and functioning, e.g. community assembly or resilience (Cadotte et al. 2011). In this perspective, several indices have recently been developed to assess the functional structure and composition of ecological communities, such as functional richness, functional divergence, or functional redundancy (de Bello et al. 2007; Villéger et al. 2008). These indices complement taxonomic approaches by decomposing diversity into facets that provide insights into niche size and complementarity within communities (Pavoine and Bonsall 2011). Additionally, recent developments of trait-based ecology have demonstrated that other facets such as functional originality (related to uniqueness in trait combinations), specialisation (related to distinctiveness in trait combinations) and rarity (assessed using 
species geographical rarity and trait rarity) were important to account for the ecology of outliers in conservation studies (Mouillot et al. 2013b; Violle et al. 2017): focusing on the conservation of functional diversity and rarity optimises biological feature preservation and decreases the probability of losing ecosystem functions (Leitão et al. 2016; Mouillot et al. 2013a). To further unravel forest fauna functional responses to temporal forest continuity, we developed an innovative approach based on spider communities. Spiders are one of the main ground-living predator arthropods. Thus, this group represents an important determinant of ecosystem functioning because spiders hold a key trophic position and regulate the soil biota both bottom-up and top-down. Moreover, contrary to taxonomic groups strongly dependent on a particular habitat (e.g. saproxylic organisms in old-growth forests) that are absent from pioneer ecosystems, their great diversity and abundance in numerous ecosystems makes them an excellent indicator of the way community structure is gradually reshaped by environmental change (Marc et al. 1999). Spider abundance and distribution are likely to change during reforestation strongly depending on vegetation structure and several other factors such as associated microclimate and litter architecture (Pearce and Venier 2006; Gallé et al. 2017). Therefore, shifts in environmental conditions during reforestation are expected to lead to variation in the composition and structure of ground-living spider assemblages (Ziesche and Roth 2008).

We analysed taxonomic and functional $\beta$ - and $\alpha$ - diversity of ground spider assemblages in forest at a regional scale with three goals: (i) identify the main broad-scale factors that influence variations in the composition (so called $\beta$-diversity) of spider communities within a regional area; (ii) assess whether spider community structure (so called $\alpha$-diversity) differs in ancient and recent forests, and (iii) assess whether spider community conservation importance also differs, using a combination of complementary $\alpha$-diversity indices based on assemblage rarity and specialisation. We used a large regional spider database to perform, for the first 
time to our knowledge, a comprehensive geographical assessment of taxonomic, structural, and functional comparisons of communities between ancient and recent forests at a broad regional scale.

\section{Materials and methods}

\section{Study sites and dataset}

We compiled data from a regional reference database including individual studies conducted in different environments in the Armorican Massif (western France) (see Leroy et al. (2013) for a presentation of the database). We extracted a subset of 56 spider assemblages sampled in forests from this database by applying a series of criteria (Fig. 1a). We selected only assemblages derived from plots of mesophilic oak-beech-dominated mature forest (for example, we avoided plantations and coniferous woodlands and young forests such as coppices), to limit the influence of environmental heterogeneity and stand maturity. These plots were homogeneous sets of $\sim 1$ ha corresponding to management units and were distributed in 16 sites across the regional area (Fig. 1, Online Resource 1). Then, we retained sites larger than 10 ha to avoid areas in which assemblages could be strongly influenced by edge effects. This selection resulted in 56 sites composed of one to six plots separated by 0.1 $\mathrm{Km}$ to $2 \mathrm{Km}$ (Online Resource 1). Within-site distances were always smaller than inter-site distances, which ranged from $5 \mathrm{Km}$ to $200 \mathrm{Km}$. Then, we set apart spider communities of ancient forests from those of recent woodlands by checking the temporal forest continuity of each forest site using Cassini map layers (year 1790) and the Napoleonic cadastre (year 1847). These two historical land-use documents allowed for a precise spatialisation of ancient forests in France. We defined ancient forests as sites already forested in the middle of the $18^{\text {th }}$ century, when the overall forested area was at its minimum over the French territory (Cateau et al. 2015). Hence, ancient forests are plots that have had an uninterrupted forest state for at 
least 220 years. Here we assume that temporal forest continuity as the absence of a historical record of agricultural land use and not as the absence of management, such as logging (Hermy and Verheyen 2007). We defined recent woodlands as forests resulting from afforestation during the $20^{\text {th }}$ century, i.e. no more than 120 years old. Thus, our dataset included 12 ancient forests (n plots=37) and 4 recent woodlands (n plots=19). Such an unbalanced design illustrates that even if farmland abandonment is an important phenomenon in Brittany, it has rarely led to the emergence of large, contiguous wooded sites. However, the recent woodlands were well distributed within study area: each of the four geographical sets of sites contained a recent woodland (Online Resource 1). Each of them are located less than $3 \mathrm{~km}$ from an ancient forest (at least a small patch). Finally, we filtered collections to retain only standardised sampling protocols based on pitfall traps and focused on forest-ground spider communities. In each plot - the experimental unit -, the local species pool was compiled from 3 pitfall traps spaced $10 \mathrm{~m}$ apart and all situated at the center of the plot. Collections were carried out from April to June (a period corresponding to the peak of spider activity in the region) of 2013, or 2014, or 2015 (see details on sampling methods in Online Resource 2). Species abundance values were standardised according to the number of days a trap was active, to account for the effect of trap disturbance. The final dataset included 5,719 adult individuals belonging to 110 spider species collected in the 56 plots.

\section{Environmental variables}

We considered nine environmental variables to characterise biogeographical, climatic, historical, and broad-scale ecological conditions at the regional scale: geological substrate (4 categories: Granite rock, Sandstone, Schist or Volcanic rock), temporal forest continuity (2 categories: ancient or recent), site area (Ha), latitude, longitude, temperature maximum in 2015 (degree Celsius), mean annual rainfall (mm), number of hours of solar radiation for the 
Page 8 on 51

174

175

1997-2006 period, and altitude (m). We compiled them from data from the French National Geographic Institute (www.geoportail.fr) and the French weather forecast institute (www.meteofrance.fr).

\section{Data analyses}

\section{Sampling effort: site richness and completeness}

We first analysed the robustness of our dataset by assessing the completeness index composed of the observed richness divided by estimated species richness (Soberón et al. 2007). We calculated three richness estimators (Chao2, Jackknife 1, and Incidence Coverage-based Estimator (ICE)) commonly applied on similar datasets (Hortal et al. 2006; Soberón et al. 2007). We calculated completeness indices for the whole dataset, for a subset composed of ancient forests and another composed of recent woodlands, and for each of the 16 sites. Richness estimators were computed with the “fossil” R package (Vavrek and Vavrek 2011).

\section{From life-history traits to functional distance between species of the regional pool}

We selected a set of five life-history traits available in the literature to describe the functional features of the 723 spider species recorded in the regional database. Seventy-eight species whose trait values were not available in the literature were excluded from our analyses. Traits were chosen to obtain a multidimensional representation of functional features of spiders describing the main facets of their ecology: body size (continuous: maximum size of females ; log-transformed to reach more symmetric distribution ; Roberts 1995), feeding guild (7 categories: ambush hunters, ground hunters, other hunters, sheet web, space web, orb web, wandering web), daily activity (3 categories: diurnal, nocturnal, both) (Cardoso et al. 2011), phenology (4 categories: spring, summer, autumn-winter, eurychron) and stratum utilisation (2 categories: ground-dwellers, vegetation-dwellers) (Harvey et al. 2002). Body size 
influences a wide range of ecological and physiological characteristics of a species (e.g. locomotion, space use, life history) and strongly affects resource use (Brose et al. 2006). Feeding guilds, phenology, stratum utilisation and daily activity are linked to resource partitioning among species and permits to analyse resource-use strategies across different sites.

To measure functional $\alpha$ - and $\beta$-diversity, we used euclidean-space-based approaches which represent the extent of niche space exploited by communities by simultaneously accounting for several traits (Fig. 1b). We built a multidimensional functional space based on the trait values of all species retained for our analyses (i.e. 645 species including all 110 species observed in our dataset of woodland communities; Online Resource 3). Because most traits were categorical, we performed a principal coordinates analysis (PCoA; with Cailliez's correction based on a Gower dissimilarity matrix computed on species traits (Villéger et al. 2008). To find the best multidimensional space possible, we used the mean-squared deviation (mSD) criterion that measured how faithfully the initial functional distances (based on trait values) were represented in the final multidimensional PCoA-based space, as recommended by Maire et al. (2015). The lower the mean-squared deviation, the higher the quality of the functional space. We thus kept 4 dimensions for the functional space $(\mathrm{mSD}=0.008)$. All functional indices were then calculated for both $\alpha$ - and $\beta$-diversity within this functional space (Fig. 1c-d).

Taxonomic and functional composition of communities: insight into overall $\beta$-diversity patterns

To quantify plot-to-plot compositional variation within and between the two forest categories, we measured pairwise dissimilarities between each pair of plots (i.e. the 56 assemblages retained after selection from the global database; Fig. 1) with Jaccard's index for the 
Page $\mathbf{1 0}$ on 51

224

225

taxonomic facet and Jaccard-derived dissimilarities for the functional facet (Villéger et al. 2013). Functional $\beta$-diversity is based on the calculation of the ratio between unshared functional space and the total functional space filled by communities in the multidimensional space (Villéger et al. 2013). In addition, we assessed the contribution of a strict turnover within taxonomic and functional $\beta$-diversity, following the frameworks of Baselga (2010) and Villéger et al. (2013), respectively. The turnover index was independent of differences in species richness (Leprieur and Oikonomou 2014), so we strictly focused on species and trait turnover in $\beta$-diversity changes. $\beta$-diversity metrics were calculated using the "betapart” $\mathrm{R}$ package (Baselga and Orme 2012).

\section{Taxonomic and functional structures of communities: insight into $\alpha$-diversity patterns}

Community structures were first investigated through three taxonomic diversity indices: species richness, species abundance and - to better understand the response of traditional taxonomic indices to temporal continuity - Pielou's evenness (which measures the evenness of abundance distribution among species). All indices that include abundance were based on standardised abundance, i.e. a continuous variable (see Table 1). To assess the functional structure of each community, we computed multivariate indices of functional diversity that measure functional distances of species from the volume of convex hull intersections in the multidimensional space. Thus, for all 110 species listed in the global species-by-site matrix, species coordinates in the overall multidimensional space were extracted to measure two complementary facets of functional diversity for each assemblage (Fig. 1c): functional richness (FRic) and functional divergence (FDiv) (Villéger et al. 2008). Furthermore, we estimated the functional redundancy (FR) of each assemblage by using the framework of de Bello et al. (2007) which measures FR as the difference between species diversity and Rao's quadratic entropy based on their functional dissimilarity (see Table 1 for metric details). 
Page 11 on 51

Finally, to quantify shifts in trait distribution, we also computed community-weighted mean trait values (CWM) and the proportion of presence-absence in each category for categorical traits, using the “FD” package in R (Laliberté et al. 2014).

Taxonomic and functional conservation importance: insight into patterns of rarity, specialisation and originality of spider communities

We used the entire regional reference database to compute conservation importance analyses; hence, the importance of each forest category was assessed with the regional species pool (i.e. the 645 species retained for our analyses; (Fig. 1d)). Concerning the taxonomic facet, we used the Index of Relative Rarity $\left(I_{\mathrm{RR}}\right)$ of Leroy et al. (2012). The $I_{\mathrm{RR}}$ is the average rarity level of each species assemblage, based on species rarity weights. Rarity weights are calculated with regional occurrence data, so that rare species are species geographically rare in the entire region. We calculated rarity weights with a method that can be adjusted according to a userchosen rarity cut-off point (Leroy et al. 2012; 2013). This method assigns rare species rarity weights that increase exponentially when their occurrence falls below the rarity cut-off point. To ensure that the chosen cut-off would be sufficient to distinguish rarity patterns among assemblages, we defined cut-offs following the guidelines of Leroy et al. 2012: the rarity cutoff was defined as the occurrence level at which the average proportion of rare species in local assemblages was 25\% (see Discussion in Leroy et al. 2012). The $I_{R R}$ of a species assemblage was calculated as the average rarity weight of all the species of the assemblage, and subsequently normalised between 0 and 1 . We used the "rarity” package (Leroy 2016) for these analyses.

Concerning the functional facet, we first used the recent framework proposed by Violle et al. (2017) to measure the functional rarity (FRar) of each assemblage. At a regional 
scale, this index is based on the two main components of species rarity (Violle et al. 2017), namely taxonomic restrictedness $\left(R_{\mathrm{i}}\right.$; regional-scale characteristic of a geographically restricted species) and functional uniqueness ( $U_{\mathrm{i}}$; regional-scale feature of a species possessing unique traits). We applied the additive framework that combines regional taxonomic restrictedness and functional uniqueness. Thus, FRar of species $i$ was estimated as the addition of $R_{i}$ and $U_{i}$ for each species recorded in the regional dataset. Finally, FRar of species from woodland assemblages were summed and then divided by species richness so that the index depended on rare species proportions but not on species richness.

Finally, we completed the assessment of forest continuity for conservation by assessing functional specialisation (FSpe) and originality (FOri) of communities. We used two multidimensional indices implemented through the framework of Mouillot et al. (2013b), which assesses the functional features of each local community in view of the species pool; see Table 1 for metrics details).

\section{Statistical significance tests}

Given the dependent structures of the dataset, we systematically integrated random effects into models to provide unbiased statistical significance tests. The chosen model structures account for hierarchical and/or spatial structures of the sampling design and make it possible to effectively avoid potential biases due to pseudoreplication (Davies and Gray 2015). Therefore, in each model (whether $\beta$ - or $\alpha$-diversity), we defined the spatial structure with regional provinces grouping nearby sites (see Online Resource 1) and the hierarchical structure (sampling plots nested within study sites) as random effects.

To analyse patterns of $\beta$-diversities, we applied permutational multivariate analysis of variance (PERMANOVAs) on dissimilarity matrices (i.e. on the previously calculated Jaccard index and Jaccard-derived dissimilarities) to check whether assemblages differed according to 
Page 13 on 51

sites ('site effect') and to temporal forest continuity ('ancientness effect'). Then, still based on the same taxonomic and functional dissimilarity matrices, we performed principal coordinate analyses (PCoA) to visualise $\beta$-diversities and highlight the structure of the species-by-site dataset (i.e. the 56 assemblages). Finally, to interpret PCoA patterns, the nine environmental variables were fitted onto ordinations. For each variable, we evaluated the significance of the explanatory power with a Monte-Carlo randomisation test (9,999 permutations), and the link strength with ordinations, using the squared correlation coefficient. For both PERMANOVAs and environmental interpretations of the PCoA, random effects were integrated by restricting permutations between regional provinces and between sites to account for the spatial and hierarchical structures of the dataset, respectively. These analyses were treated with the “vegan” and “permute” R packages (Oksanen et al. 2017; Simpson et al. 2016).

To analyse patterns of $\alpha$-diversity, we tested the means of each continuous metrics (i.e. FRic, FOri) in ancient versus recent woodlands with linear mixed-effect models (LMMs). For species richness, which is a discrete variable, we used generalised linear mixed-effect models (GLMMs). For all models, temporal forest continuity was defined as a fixed effect, and regional provinces and sites as random effects. We log-transformed values of standardised abundance, $I_{\mathrm{RR}}$, FOri and FSpe to improve model fitness. We used the "Ime4" package (Bates et al. 2015) for these analyses.

All data analyses were performed using R version 3.4.1 (R Core Team 2017).

\section{Results}

\section{Sampling effort: site richness and completeness}

On average, $19.01 \pm 5.57$ (mean \pm sd) species were sampled per site, ranging from 13 to 47 . The mean value of the three selected completeness estimators for the overall dataset was 
Page 14 on 51

relatively high $(0.83 \pm 0.04)$, suggesting that the information extracted from the database gave us a fairly satisfactory picture of the species composition of the spider communities observed in the forest environments we studied (Online Resource 4). Out of the 16 sites, two (Rennes, Stangala) displayed low values ( 0.65 and 0.66 , respectively), and four others had no estimable values because the number of samples was too low (Bois du Chap, Cranou, Menez, and Sœuvres).

\section{Regional patterns of taxonomic and functional dissimilarities}

Pairwise dissimilarities of spider assemblages were high and quite similar (they ranged from 0.66 to 0.74 for the taxonomic facet and from 0.76 to 0.82 for the functional facet across the entire study area, within and also between the two forest categories (Table 2)). In each case, pairwise functional dissimilarities were greater than taxonomic ones. However, when variation in species richness was controlled by focusing on the contribution of turnover to pairwise dissimilarities, functional variations were systematically lower than taxonomic variations (from 0.40 to 0.46 and from 0.56 to 0.67 , respectively).

\section{Sources of variation in taxonomic and functional dissimilarity}

PERMANOVA results highlighted significant differences in the taxonomic composition of spider communities across the 16 forest sites and between the two forest categories. The "site" factor explained more than half of overall variance in the regional area $\left(R^{2}=0.518 ; p=0.001\right)$ whereas the "temporal forest continuity" factor explained around 1/10 $\left(R^{2}=0.096 ; p=0.001\right)$. PERMANOVAs applied to functional composition also highlighted significant differences across the 16 forest sites $\left(R^{2}=0.38 ; p=0.001\right)$. Differences were likewise significant between the two forest categories, but the part of the explained variance was very low $\left(R^{2}=0.034 ; p=\right.$ $0.01)$. 
Page 15 on 51

Our analyses of the taxonomic facet showed a strong separation between spider communities of ancient and recent forests on the PCoA (Fig. 2). Regardless of their geographical position, the communities sampled in the recent woodlands were all more similar to one another than they were to their geographic neighbours from ancient forests; and the reverse was true for ancient forest communities (Fig. 2; Online Resource 1). Thus, when the influence of the temporal forest continuity was analysed through the fitting of environmental variables within the ordination space, it appeared as one of the main factors leading to the taxonomic compositional variation within the regional area $\left(\mathrm{r}^{2}=0.35, p=0.001\right.$; Table 3). Additionally, PCoA revealed that the taxonomic composition was also strongly influenced by the geographical locations and climatic conditions of the sites: on the one hand, spider communities clearly and strongly differed according to altitude and latitude $\left(r^{2}=0.58\right.$ and $r^{2}=0.54$, respectively; Fig. 2; Table 3); on the other hand, the composition of spider communities was also significantly (but more slightly) correlated with solar radiation and longitude ( $r^{2}=0.34$ and $r^{2}=0.20$, respectively; Fig. 2; Table 3). Among the other four variables, "area of sites”, "rainfall” and "geological substrate” also had an influence, but to a much lesser extent $\left(r^{2}<0.15\right)$, while "temperature” was not significant.

Our analyses of the functional facet suggest that spider communities of recent and ancient forests were not distinguishable on the PCoA (Fig. 2). Only longitude and temperature were significantly correlated with the ordination $\left(r^{2}=0.18 ; p=0.01\right.$ in both cases; Table 3$)$.

The two-axis PCoA performed at the taxonomic level summarised $21 \%$ of the variance of the Jaccard dissimilarity matrix, but the pairwise distances plotted onto the ordination space were proportional to the observed ones (indicated by the fact that the cloud of points approximately followed a straight line; see Shepard diagram in Online Resource 6).

371 Concerning the functional facet, the PCoA summarised a larger part of the variance (28\%), 372 but less accurately so (Online Resource 6). 
Page 16 on 51

\section{Community structure and conservation importance}

The mean values of all the metrics describing community structure at the taxonomic (species richness, standardised abundance, evenness) and functional (functional richness, divergence, redundancy) levels did not differ between ancient forests and recent woodlands (Wald's test; $p>0.05$; Fig. 3; Online Resource 5). Similarly, the metrics describing taxonomic $\left(I_{\mathrm{RR}}\right)$ and functional (FRar) rarity in the two forest environments did not differ, nor did functional specialisation (Wald's test; $p>0.05$ ). In contrast, average functional originality of groundliving spider communities was significantly higher in ancient forests than in recent woodlands (Wald's test $=12.9 ; p=0.0003$ ) (Fig. 4; Online Resource 5).

Additionally, several mean trait distributions (assessed with CWMs) showed significant differences between ancient and recent forests (Fig. 5; Online Resource 5). Thus, mean body size, the proportion of species carrying out their life cycle in autumn/winter, and the proportion of various hunters (called other hunters) were significantly higher in the communities of ancient forests (Wald's test $=4.75 ; p=0.03$ ); the proportion of ground hunters was marginally higher in the ancient forests (Wald's test $=3.6$; $p=0.056$ ). On the other hand, there were significantly more orb-web and space-web spiders as well as more vegetation-dweller species in the recent woodlands than in the ancient forests (Wald's tests = $4.3,8.9,16.9 ; p=0.04,0.003,<0.0001$, respectively); the proportion of species active both in the daytime and at night was marginally higher in the recent woodlands (Wald's test $=3.7 ; p$ $=0.053)$. Nine out of the 16 investigated traits did not show any differences between the two forest categories.

\section{Discussion}

Based on the available data at a regional scale, our study provides new insights into the ecological specificity of ancient and recent forests by comparing taxonomic and functional $\beta$ - 
and $\alpha$-diversity of ground-living spider assemblages. We obtained three main findings. First, taxonomic and functional composition of spider communities greatly varied within the study area, with lower biotic homogeneity at a regional scale than we expected. Second, we observed significant differences in species composition and trait distribution between ancient and recent forests. On the other hand, $\beta$-diversity converged when the composition was characterised from a functional point of view (the extent of trait distribution, not their mean). Third, the community structure and conservation importance of the two forest categories did not reveal significant differences, except for functional originality.

\section{Compositional specificity of forest sites within the regional area}

We found strong plot-to-plot variations ( $\beta$-diversity) in taxonomic and functional composition within and between the forests (Jaccard dissimilarities $>0.7$, Table 2). In addition, the relative part of strict functional turnover was lower than the taxonomic one (0.44 and 0.61 , respectively; Table 2). This interesting finding suggests that species replacement did not systematically lead to a shift in functional composition and suggests probable trait redundancy in spider communities inhabiting forest environments in our region.

These compositional differences - especially taxonomic ones - were strongly linked to site identities (see PERMANOVA results). This result suggests that each forest site exhibited to some extent an original composition of ground-living spider communities, and, to a lesser extent, distinct combinations of life-history traits. Temporal forest continuity appeared as one of the major factors explaining taxonomic $\beta$-diversity among spider communities; this was especially represented by one of the two major axes of taxonomic compositional variation within the regional area (Fig. 2). In addition, other environmental characteristics of the sites (altitude, latitude, solar radiation, longitude) also significantly influenced global dissimilarity and represented the second major axis of taxonomic compositional variation. We thus found 
that the main sources of taxonomic and - to a lesser extent - functional $\beta$-diversity were the geographical positions of the forests within the regional area, i.e. the longitudinal and latitudinal coordinates of the sites as well as their altitudes (Table 3). Combined with the other geographical differences in parameters such as rainfall, temperature, or solar radiation, the strong effects of these variables suggest a great influence of broad-scale climatic conditions on the regional $\beta$-diversity of forest spider communities. These results are consistent with our knowledge of niche properties of spiders that are conditioned by the interplay of a few abiotic factors strongly linked to climatic conditions, namely shading and moisture (Entling et al. 2007).

A secondary significant source of taxonomic $\beta$-diversity was the geological substrate. Thus, although we restricted our investigations to one forest type (i.e. oak- and beechdominated woodlands), this finding may suggest that our dataset included contrasting vegetation types and physiognomies linked to geological substrates and, as a corollary, distinct spider communities. Plant community composition indeed strongly influences arthropod assemblages, including predators, because of numerous causal factors (e.g. vegetation structure, predator-prey interactions, microclimatic conditions) that affect invertebrate distribution (Schaffers et al. 2008). The surface area of sites also captured a significant part of the variance of taxonomic dissimilarities, suggesting that site periphery influenced species composition. Landscape structure influences the composition of spider assemblages because it drives the availability of surrounding habitat sources (Öberg et al. 2007) and edge habitats (Pearce et al. 2005). More specifically, smaller forest patches could be occupied by open-habitat specialist spiders absent in large forests because their high edgeto-area ratio favours an edge effect and individual moving (Gallé 2008).

Beyond these significant relationships between $\beta$-diversity and sites broad-scale ecological characteristics, a large part of overall taxonomic and functional $\beta$-diversity 
Page 19 on 51

remained unexplained (48\% of total variance, see PERMANOVA results). A first explanation could be linked to fine-scale ecological parameters that we did not evaluate (e.g. see Pinzon et al. 2018), and which could lead to environmental heterogeneity of forest biota. Several factors can affect spider community composition, such as vegetation structure, litter architecture, or such as micro-climate, soil moisture, soil type, organic matter content, $\mathrm{pH}$, fertility, as well as management practices (see Prieto-Benítez and Méndez 2011; Schaffers et al. 2008). A second explanation may arise from stochastic processes such as probabilistic colonisation (Mallis and Hurd 2005) or historical contingencies. The ranking and timing of species immigration during colonisation processes, known as priority effects, can also affect local occurrence and abundance and may generate various patterns of species composition (Fukami 2015). Finally, temporal fluctuations of the abundance of spider populations affect their detectability and may also influence the geographical patterns observed in species composition (Gossner et al., 2014). This could increase differences among communities when comparisons are based on results of pluri-annual field surveys. In this context, it would be interesting to complete our investigations by a study integrating a longer sampling period that would smooth out the potential phenological variations across sites.

\section{Trees do not make forests: major differences in taxonomic composition, and shifts in}

\section{trait distribution between ancient and recent forests}

Our findings provide clear evidence that taxonomic composition of ground-living spider communities significantly differs between ancient and recent forests. Spider communities sampled in the same type of forest were more alike than spider communities sampled in different types of forest, regardless of their geographical positions. On the other hand, we did not find any difference in functional $\beta$-diversity between forest categories; but we found significant differences in the life-history trait distributions (Fig. 2; Fig. 5). Altogether, these 
Page 20 on 51

473 results are consistent with our expectations that forest continuity leads to ecological

474 differences between woodlands and in turn generates various compositional patterns by 475 affecting spider niche properties. It is now well known that recent woodlands differ 476 ecologically from ancient forests (see the review by Hermy and Verheyen 2007). These 477 ecological differences are mainly due to agricultural legacies that may sometimes strongly 478 and lastingly impact soil properties such as $\mathrm{pH}$, organic matter, carbon/nitrogen/phosphate

479 480 contents, and in turn pedofauna and vegetation composition (Dupouey et al. 2002; Flinn and Marks 2007). Changes in soil physicochemical properties and associated food webs (i.e. brown and green food webs) in turn affect upper trophic levels such as arthropod predators by influencing local microclimates, habitat structure or prey availability (Pearce and Venier 2006; Ziesche and Roth 2008). As a consequence, given the weak dispersal abilities and the strong association of forest specialist arthropods to micro-habitats and physical conditions of woodlands (i.e. moisture and shadow), their potential establishment in recent re-growth forests needs time (Bowen et al. 2007; Spake et al. 2015). This greater proportion of specialised species (occupying a restricted niche) in ancient forests is especially illustrated in terms of traits by the overrepresentation of species that carry out their life cycles in autumn/winter as compared to recent woodlands (Fig. 5). This was the case for Centromerus brevipalpus or Hahnia ononidum, two strictly forest-dwelling spiders (Online Resource 3, Online Resource 7). Otherwise, these compositional differences between the two types of forests may also result from the temporary maintenance of species associated to earlier successional stages in recent woodlands. We indeed observed that values or categories of lifehistory traits that can favour the colonisation of new habitats were better represented in recent forests than in ancient forests. These traits included a small size, generalist traits such as large daily activity (both diurnal and nocturnal), or membership in hunting guilds primarily using webs (Fig. 5), because such traits make species more prone to dispersal (ballooning) and less 
Page $\mathbf{2 1}$ on $\mathbf{5 1}$

498

499

500

501

502

503

504

505

506

507

508

509

510

511

512

513

514

515

516

517

518

519

520

521

522

dependent on the soil biota (Nentwig 1986; Gobbi 2017). This is typically the case of the Lynyphiidae family. Moreover, temporal continuity could interact with stand maturity and cause variations in species composition (Janssen et al. 2017). Thus, although we carefully selected forest plots with similar maturity, a few compositional differences may have been related to structural attributes such as dead-wood material or litter complexity, which also influence spider distribution (Buddle 2001; Bultman et al. 1982). This is the case for some species more specifically found under dead wood stumps or forest floor stones (e.g. the large cribellate spider Amaurobius similis or the sheet-weaving spider with tubular retreat Eritagena picta). Future investigations should account for this distinction and refine our understanding of the influence of forest continuity on spider community structuring. Finally, some of these compositional differences may not be linked to deterministic factors: as predicted by the theory of community assembly, stochastic forces such as historical contingency (e.g. priority effects) or neutral processes such as dispersal and ecological drift may interact with environmental filtering and biotic interactions to shape communities and partly result in unpredictable assemblages (Chase 2003; Fukami 2015).

\section{Trees make forests: convergence of community structures between ancient and recent}

\section{forests}

Despite differences in taxonomic composition and trait distribution, functional $\beta$-diversity, community structure and conservation importance were highly similar in the two forest categories. A first consequence is that the degrees of functionality ensured by spider communities in both ancient and recent forests seemed unchanged: functional richness suggests that niche sizes (i.e. the volumes of functional space) exploited by spider communities were identical (Fig. 3a-b). Furthermore, the consistency of abundance values and the high values of Pielou's evenness index suggest that ecological niches were exploited 
with the same intensity, i.e. species shared available resources similarly in ancient and recent forests (Fig. 3c-e). The lack of differences in functional divergence shows that the degrees of niche differentiation in the communities were also similar (Fig. 3d) (Mouchet et al. 2010; Villéger et al. 2008). Additionally, the same levels of functional redundancy suggest that spider species performed similar functions in the two forest categories and were therefore interchangeable, with little impact on ecosystem processes (Fig. 3f) (Fonseca and Ganade 2001). The low $I_{\mathrm{RR}}$ values revealed that the communities of the ancient and recent forests were dominated by species otherwise widespread in western France. Moreover, ancient forests did not harbour communities with rarer functional features than recent woodlands relatively to the regional area (Fig. 4a-b). Similarly, functional specialisation of forest spider communities did not differ over time, suggesting similar widths of the ecological niches exploited by spiders in all forest environments (Fig. 4d). Previous studies investigating biodiversity responses to farmland abandonment found that fauna taxonomic structure in secondary forests could rapidly resemble fauna taxonomic structure of ancient forests (Bowen et al. 2007; Spake et al. 2015). More precisely, no difference in $\alpha$-diversity between ancient and recent forests was found in communities of ground-living beetles (Assmann 1999) and spiders (Hurd and Fagan 1992) in temperate ecosystems. By highlighting similar trends with functional metrics, our results are in line with research showing that recent woodlands can spontaneously recover forest fauna weakly impeded by dispersal constraints, including many arthropod groups (Nordén et al. 2014; Queiroz et al. 2014). Finally, these results raise the important question of which conditions generate such rapid and spontaneous recovery of structures of ecological communities. Can these processes also be observed after the abandonment of agrosystems intensively exploited during the $20^{\text {th }}$ century?

In contrast with these similarities between the two forest categories, we evidenced that ancient forests harboured functionally more original assemblages (Fig. 4c). A first potential 
Page $\mathbf{2 3}$ on $\mathbf{5 1}$

consequence is that ancient forests tend to harbour on average more functionally original species than recent woodlands do. In other words, species of ancient forests seem to be isolated within the functional space of the regional species pool. Among these species, several are known to be specific to habitat conditions more frequently found in ancient forests. For example, Neon reticulatus or Saloca diceros are two small litter-hunter specialist species generally associated with a dense leaf litter, exhibiting one of the most important values of functional originality, and only recorded in ancient forests (Online Resource 7a; Online Resource 3). Yet, there were also other species exclusively present in recent woodlands which showed high degrees of functional originality as well as analogous functional features to those exclusively present in ancient forests. For example, Neriene clathara and Linyphia hortensis are two small sheet web linyphiidae observed exclusively in ancient forests and recent woodlands, respectively (Online Resource 7a; Online Resource 3). This result, combined with the fact that exclusive species are rare (Online Resource 7a), suggests that differences in species composition were not the only parameter explaining the mean differences in FOri between the two forest categories. The higher FOri of the spider communities of ancient forests likely also resulted from the greater representation (in terms of abundance) of functionally distinct species (e.g. forest specialists such as Apostenus fuscus or forest generalists such as Pardosa saltans; Online Resource 7a). Overall, whether in terms of species distribution or abundance, the most original forest spiders appear to be favoured in ancient forests, either because temporal continuity allows for the maintenance of populations over time, or because habitat conditions are better suited to their biological cycles. The fact that functional original spiders might be favoured in ancient forests is an interesting finding because it provides functional perspectives to previous works highlighting the importance of ancient forests to preserve highly stenoecous and relict arthropod species (Assmann, 1999; Buse, 2012). 
Page $\mathbf{2 4}$ on $\mathbf{5 1}$

573

574

\section{Study limitations}

Despite our efforts to improve the reliability of our dataset and the robustness of the analyses, our results should be interpreted considering the methodological limitations inherent to large datasets compiling different individual studies. Our main limitation lies in the fact that our design was unbalanced, with a larger number of plots sampled in ancient forests than in recent woodlands ( $\mathrm{n}=37$ vs. $\mathrm{n}=19$ ). This imbalance was reflected in the lower global completeness value of recent woodlands, suggesting that these communities were sampled less accurately, even though two of the three estimators had similar values to those of ancient forests (Online Resource 4). In addition, most sites, whether ancient or recent, had relatively high completeness ( $>0.75)$. Nevertheless, this imbalance may have influenced both metrics related to geographic rarity ( $I_{\mathrm{RR}}$, FRar) because of a greater probability to detect rare species in ancient forests than in recent woodlands. However, this bias seemed to have little influence on our results: spider communities of ancient forests did not show higher values for $I_{\mathrm{RR}}$ or FRar (Fig. 4a-b), and their variances were homogeneous between the two forest categories $(F$ test $=$ 1.66, $1.87 ; p=0.25,0.16$, respectively; $\left.d f_{\text {num. }}=36, d f_{\text {den }} .=18\right)$. These results suggest that, even with fewer pitfall traps, the distribution of these rarity values in the recent woodlands was similar to that of ancient forests. However, we consider our study as a first approach to examine the response of forest spider assemblages to farmland abandonment. This first approach is paving the way for future works based on more exhaustive data (both in terms of time and space), which will also account for fine-scale ecological parameters (e.g. abiotic soil conditions) and finer life-history traits, and complete our results. Overall, we feel that a collective research effort focusing on spontaneous rewilding would be welcome to assess to what extent and under which conditions recent afforestation may significantly contribute to the conservation of forest arthropods. 
Page $\mathbf{2 5}$ on $\mathbf{5 1}$

598

599

600

601

602

603

604

605

606

607

608

609

610

611

612

613

614

615

616

617

618

619

620

621

\section{Concluding remarks}

The present study shows that, combined with broad-scale ecological factors, temporal continuity contributes to generate various assemblages among forest sites. In a conservation perspective, this is an interesting result because it demonstrates that each forest, whether ancient or recent, is not equivalent and contributes to regional biodiversity. Thus, our results suggest that ground-living spider communities of ancient forests are irreplaceable because of their compositional uniqueness and high functional originality. However, by showing that communities with structural and functional profiles very similar to those of ancient forests can be recovered within a century, our results also highlight the promising conservation role possibly played by recent woodlands in times of global land-use changes.

\section{Acknowledgements}

This work was supported by the 'Région Bretagne', 'Conseil départemental des Côtes d’Armor', 'Conseil départemental Finistère’, 'Conseil départemental d’Ille et Vilaine’, ‘Conseil départemental du Morbihan’ and ‘Communauté de communes de Plouha-Lanvollon’ for technical and financial support. Moreover, we also would like to thank the military camp of St-Cyr-Coëtquidan and especially Alexandra Baudart and Sébastien Gautier (ONCFS) as well as Nicolas Le Deuff, Guy Le Reste (ONF) and David Rolland (FDC 22) for their help in acquiring data. We are also very grateful to the many colleagues and friends who helped in the preparation, analysis and treatment of data: Simon Chollet, Pierre Devogel, Maxime Hervé, Vincent Jung, Jean-Paul Lechapt, Margot Morin, Melaine Roullaud and Manon Simoneau, as well as the three anonymous reviewers for their careful reading of our manuscript and their many insightful comments and suggestions. We are also very grateful to Diane Morel for the two drawings included in Figure 2. 
622

623

624

625

626

627

628

629

630

631

632

633

634

635

636

637

638

639

640

641

642

643

644

645

646

647

648

649

650

651

652

653

654

655

656

657

658

\section{References}

Allan E, Manning P, Alt F, Binkenstein J, Blaser S, Blüthgen N et al. (2015) Land use intensification alters ecosystem multifunctionality via loss of biodiversity and changes to functional composition. Ecol Lett 18: 834-843.

Assmann T (1999) The ground beetle fauna of ancient and recent woodlands in the lowlands of north-west Germany (Coleoptera, Carabidae). Biodivers Conserv 8:1499-1517.

Baselga A (2010) Partitioning the turnover and nestedness components of beta diversity. Global Ecol Biogeogr 19: 134-143.

Baselga, A, Orme CDL (2012) betapart: an R package for the study of beta diversity. Methods Ecol Evol 3: 808-812.

Bates D, Maechler M, Bolker B, Walker S (2015) Fitting Linear Mixed-Effects Models Using lme4. J Stat Softw 67(1): 1-48.

Bello F, Lepš J, Lavorel S, Moretti M (2007) Importance of species abundance for assessment of trait composition: an example based on pollinator communities. Community Ecol 8:163170.

Bowen ME, McAlpine CA, House APN, Smith GC (2007) Regrowth forests on abandoned agricultural land: A review of their habitat values for recovering forest fauna. Biol Conserv 140: 273-296.

Brose U, Jonsson T, Berlow EL, Warren P, Banasek-Richter C, Bersier L-F., Blanchard JL, Brey T, Carpenter SR, Blandenier M-FC, Cushing L, Dawah HA, Dell T, Edwards F, HarperSmith S, Jacob U, Ledger ME, Martinez ND, Memmot, J, Mintenbeck K, Pinnegar JK, Rall BC, Rayner TS, Reuman DC, Ruess L, Ulrich W, Williams RJ, Woodward G, Cohen JE (2006) Consumer-resource body-size relationships in natural food webs. Ecology 87: 24112417.

Buddle CM (2001) Spiders (Araneae) associated with downed woody material in a deciduous forest in central Alberta, Canada. Agr Forest Entomol 3: 241-251.

Bultman TL, Uetz, GW, Brady AR (1982) A comparison of cursorial spider communities along a successional gradient. J Arachnol 10: 23-33.

Buse J (2012) “Ghosts of the past”: flightless saproxylic weevils (Coleoptera: Curculionidae) are relict species in ancient woodlands. J Insect Conserv 16: 93-102.

Cadotte MW, Carscadden K, Mirotchnick, N (2011) Beyond species: functional diversity and the maintenance of ecological processes and services: Functional diversity in ecology and conservation. J Appl Ecol 48: 1079-1087.

Cardoso P, Pekár S, Jocqué R, Coddington JA (2011) Global Patterns of Guild Composition and Functional Diversity of Spiders. PLoS ONE 6: e21710.

Cateau E, Larrieu L, Vallauri D, Savoie J-M, Touroult J, Brustel H (2015) Ancientness and maturity: two complementary qualities of forest ecosystems. C R Biol 338 : 58-73. 
659

660

661

662

663

664

665

666

667

668

669

670

671

672

673

674

675

676

677

678

679

680

681

682

683

684

685

686

687

688

689

690

691

692

693

Chase JM (2003) Community assembly: when should history matter? Oecologia 136: 489498.

Davies GM, Gray A (2015) Don't let spurious accusations of pseudoreplication limit our ability to learn from natural experiments (and other messy kinds of ecological monitoring). Ecol Evol 5(22): 5295-5304.

Desender, K, Ervynck A, Tack G (1999) Beetle diversity and historical ecology of woodlands in Flanders. Belg J Zool 129:139-156.

Dupouey J-L, Dambrine E, Laffite J-D, Moares C (2002) Irreversible impact of past land use on forest soils and biodiversity. Ecology 83: 2978-2984.

Entling W, Schmidt MH, Bacher S, Brandl R, Nentwig W (2007) Niche properties of Central European spiders: shading, moisture and the evolution of the habitat niche. Global Ecol Biogeogr 16: 440-448.

Flinn KM, Marks PL (2007) Agricultural Legacies in Forest Environments: Tree Communities, Soil Properties, and Light Availability. Ecol Appl 17: 452-463.

Fonseca CR, Ganade G (2001) Species functional redundancy, random extinctions and the stability of ecosystems. J Ecol 89: 118-125.

Fukami T (2015) Historical Contingency in Community Assembly: Integrating Niches, Species Pools, and Priority Effects. Annu Rev Ecol Evol S 46: 1-23.

Gallé R (2008) The effect of a naturally fragmented landscape on the spider assemblages. North-West J Zool 4: 61-71.

Gallé R, Gallé-Szpisjak N, Torma A (2017) Habitat structure influences the spider fauna of short-rotation poplar plantations more than forest age. Eur J Forest Res 136 : 51-58.

Gobbi M, Ballarin F, Brambilla M, Compostella M, Isaia M, Losapio G, Maffioletti C, Seppi R, Tampucci D, Caccianiga M (2017) Life in harsh environments: carabid and spider trait types and functional diversity on a debris-covered glacier and along its foreland. Ecol Entomol 42 : $838: 848$.

Goßner M, Engel K, Jessel B (2008) Plant and arthropod communities in young oak stands: are they determined by site history? Biodiver Conserv 17: 3165-3180.

Gossner MM, Fonseca CR, Pašalić E, Türke M, Lange M, Weisser WW (2014) Limitations to the use of arthropods as temperate forests indicators. Biodiver Conserv 23: 945-962.

Harvey PR, Nellist DR, Telfer MG (2002) Provisional Atlas of British Spiders (Arachnida, Araneae), Biological Records Center. Huntington, UK.

Hermy M, Honnay O, Firbank L, Grashof-Bokdam C, Lawesson JE (1999) An ecological comparison between ancient and other forest plant species of Europe, and the implications for forest conservation. Biol conserv 91: 9-22. 
694

695

696

697

698

699

700

701

702

703

704

705

706

707

708

709

710

711

712

713

714

715

716

717

718

719

720

721

722

723

724

725

726

727

728

729

Hermy M, Verheyen K (2007) Legacies of the past in the present-day forest biodiversity: a review of past land-use effects on forest plant species composition and diversity. Ecol Res 22: 361-371.

Hobbs RJ, Higgs E, Hall C.M (2013) Novel ecosystems: intervening in the new ecological world order. Wiley-Blackwell, Chichester, UK.

Hortal J, Borges PAV, Gaspar C (2006) Evaluating the performance of species richness estimators: sensitivity to sample grain size. J Anim Ecol 75: 274-287.

Hurd LE, Fagan WF (1992) Cursorial spiders and succession: age or habitat structure? Oecologia 92: 215-221.

Janssen P, Fuhr M, Cateau E, Nusillard B, Bouget C (2017) Forest continuity acts congruently with stand maturity in structuring the functional composition of saproxylic beetles. Biol conserv 205: 1-10.

Kirby K, Watkins C (2015) Europe's Changing Woods and Forests: From Wildwood to Managed Landscapes. CAB Int, Wallingfor.

Laliberté E, Legendre P, Shipley B (2014) FD: measuring functional diversity from multiple traits, and other tools for functional ecology. R package version 1.0-12.

Leitão RP, Zuanon J, Villéger S, Williams SE, Baraloto C, Fortune, C, Mendonça FP, Mouillot D (2016) Rare species contribute disproportionately to the functional structure of species assemblages. P Roy Soc B-Bio Sci 283: 20160084.

Leprieur F, Oikonomou A (2014) The need for richness-independent measures of turnover when delineating biogeographical regions. J Biogeogr 41: 417-420.

Leroy B (2016) Rarity: Calculation of rarity indices for species and assemblages of species. R package version 1-3-6.

Leroy B, Canard A, Ysnel F (2013) Integrating multiple scales in rarity assessments of invertebrate taxa. Divers Distrib 19: 794-803.

Leroy, B, Petillon, J, Gallon, R, Canard, A, Ysnel, F, 2012 Improving occurrence-based rarity metrics in conservation studies by including multiple rarity cut-off points: Multiple cut-offs in rarity metrics. Insect Conservation and Diversity 5, 159-168.

Magura T, Bogyó D, Mizser S, Nagy DD, Tóthmérész B (2015) Recovery of ground-dwelling assemblages during reforestation with native oak depends on the mobility and feeding habits of the species. Forest Ecol Manag 339: 117-126.

Maire E, Grenouillet G, Brosse S, Villéger S (2015) How many dimensions are needed to accurately assess functional diversity? A pragmatic approach for assessing the quality of functional spaces: Assessing functional space quality. Global Ecol Biogeogr 24: 728-740.

Mallis RE, Hurd LE (2005) Diversity among ground-dwelling spider assemblages: habitat generalists and specialists. J Arachnol 33: 101-109. 
Marc P, Canard A, Ysnel F (1999) Spiders (Araneae) useful for pest limitation and bioindication. Agric Ecosyst Environ 74: 229-273.

Miller JR, Bestelmeyer BT (2016) What's wrong with novel ecosystems, really? Restor Ecol 24: 577-582.

Mouchet MA, Villéger S, Mason NWH, Mouillot D (2010) Functional diversity measures: an overview of their redundancy and their ability to discriminate community assembly rules. Funct Ecol 24, 867-876.

Mouillot D, Bellwood DR, Baraloto C, Chave J, Galzin R, Harmelin-Vivien M, Kulbicki M, Lavergne S, Lavorel S, Mouquet N, Paine CET, Renaud J, Thuiller W (2013a) Rare Species Support Vulnerable Functions in High-Diversity Ecosystems. PLOS Biology 11: e1001569.

Mouillot D, Graham NAJ, Villéger S, Mason NWH, Bellwood DR (2013b) A functional approach reveals community responses to disturbances. Trends Ecol Evol 28: 167-177.

Murcia C, Aronson J, Kattan GH, Moreno-Mateos D, Dixon K, Simberloff D (2014) A critique of the 'novel ecosystem' concept. Trends Ecol Evol 29: 548-553.

Nentwig G (1986) Non-webbuilding spiders: prey specialists or generalists? Oecol 69: 571576.

Newbold T, Hudson LN, Hill SLL, Contu S, Lysenko I, Senior RA et al (2015) Global effects of land use on local terrestrial biodiversity. Nature, 520: 45-50.

Nordén B, Dahlberg A, Brandrud TE, Fritz Ö, Ejrnaes R, Ovaskainen O (2014) Effects of Ecological Continuity on Species Richness and Composition in Forests and Woodlands: A Review. Ecoscience 21: 34-45.

Öberg S, Ekbom B, Bommarco R (2007) Influence of habitat type and surrounding landscape on spider diversity in Swedish agroecosystems. Agric Ecosyst Environ 122: 211-219.

Oksanen J, Blanchet FG, M Friendly, Kindt R, Legendre P, McGlinn D, Minchin RB, O’Hara RB, Simpson GL, Solymos P, Stevens MHH, Wagner ES, Wagner H (2017) vegan: Community Ecology Package. R package version 2-4-4.

Pavoine S, Bonsall MB (2011) Measuring biodiversity to explain community assembly: a unified approach. Biol Rev 86: 792-812.

Pearce JL, Venier LA (2006) The use of ground beetles (Coleoptera: Carabidae) and spiders (Araneae) as bioindicators of sustainable forest management: A review. Ecol Indic 6: 780793.

Pearce JL, Venier LA, Eccles G, Pedlar J, MCKenney D (2005) Habitat Islands, Forest Edge and Spring-active Invertebrate Assemblages. Biodiver Conserv 14: 2949-2969.

Pereira HM, Navarro LM (Eds.) (2015) Rewilding European Landscapes. Springer, NewYork.

Pinzon J, Wu L, He F, Spence JR (2018) Fine-scale forest variability and biodiversity in the boreal mixedwood forest. Ecography 41: 753-769. 
Prieto-Benítez S, Méndez M (2011) Effects of land management on the abundance and richness of spiders (Araneae): a meta-analysis. Biol Conserv 144: 683-691.

Queiroz C, Beilin R, Folke C, Lindborg R (2014) Farmland abandonment: threat or opportunity for biodiversity conservation? A global review. Front Ecol Environ 12: 288-296.

R Core Team (2017) R: A language and environment for statistical computing. R Foundation for Statistical Computing, Vienna, Austria.

Renwick A, Jansson T, Verburg PH, Revoredo-Giha C, Britz W, Gocht A, McCracken D (2013) Policy reform and agricultural land abandonment in the EU. Land Use Policy 30: 446457.

Roberts MJ (1995) Spiders of Britain \& Northern Europe Harper Collins, London; New York.

Sala OE (2000) Global Biodiversity Scenarios for the Year 2100. Science 287: 1770-1774.

Schaffers AP, Raemakers IP, Sỳkora KV, Ter Braak CJ (2008) Arthropod assemblages are best predicted by plant species composition. Ecology 89: 782-794.

Simpson GL (2016) permute: Functions for Generating Restricted Permutations of Data. R package version 0.9-4.

Soberón J, Jiménez R, Golubov J, Koleff P (2007) Assessing completeness of biodiversity databases at different spatial scales. Ecography 30: 152-160.

Spake R, Ezard THG, Martin PA, Newton AC, Doncaster CP (2015) A meta-analysis of functional group responses to forest recovery outside of the tropics. Conserv Biol 29: 16951703.

Vavrek MJ, Vavrek MMJ (2011) fossil: palaeoecological and palaeogeographical analysis tools. Palaeontol Electronica 14:1T.

Villéger S, Grenouillet $\mathrm{G}$, Brosse S (2013) Decomposing functional $\beta$-diversity reveals that low functional $\beta$-diversity is driven by low functional turnover in European fish assemblages: Decomposing functional $\beta$-diversity. Global Ecol Biogeogr 22: 671-681.

Villéger S, Mason NW, Mouillot D (2008) New multidimensional functional diversity indices for a multifaceted framework in functional ecology. Ecology 89: 2290-2301.

Violle C, Thuiller W, Mouquet N, Munoz F, Kraft NJB, Cadotte MW, Livingstone SW, Mouillot D (2017) Functional Rarity: The Ecology of Outliers. Trends Ecol Evol 32: 356367.

Ziesche TM, Roth M (2008) Influence of environmental parameters on small-scale distribution of soil-dwelling spiders in forests: What makes the difference, tree species or microhabitat? Forest Ecology and Management 255: 738-752. 
Page 31 on 51

803

804

805

806

807

808

809

810

811

812

813

814

815

816

817

818

819

820

821 Fig. 4 Composite view of conservation value of spider' communities of ancient forests and

822

823

824

\section{Figures captions}

Fig. 1 Overview of the step-by-step analytical framework (see Materials and Methods for details).

Fig. 2 Ordination of the taxonomic and functional compositions of spider assemblages by principal coordinate analyse (PCoA) for the 56 assemblages (37 ancient forests and 19 recent woodlands). Overlap between spider communities of ancient forests (turquoise) and recent woodlands (red) is illustrated with one- (top and right of each graph) and two-dimensional kernel density (outer hull for 75\%). The direction and the strength of the continuous environmental variables are represented by black arrows in each ordination (only significant variables; see Table 3). The strength of each variable is shown by the length of the arrow that is proportional to the correlation with ordination. The four symbols show the four identified groups of nearby sites (Online Resource 1).

Fig. 3 Structure, taxonomic and functional $\alpha$-diversity of spider communities in ancient forests $(n=37)$ and recent woodlands $(n=19)$. Graphs show boxplots and means \pm standard errors. See methods for further details on the calculation of these indices.

recent woodlands combining taxonomic indicators (a) and functional metrics (b,c,d). Graphs show both boxplots and mean \pm standard errors. See methods for further details on the calculation of these indices. 
Page 32 on 51

825 Fig. 5 Community-weighted mean (CWM) body size and proportion of presence-absence in 826 each category for categorical traits of spider communities in ancient forests $(n=37)$ and recent 827 woodlands ( $n=19)$. Graphs show boxplots and means \pm standard errors. CWMs between the 828 two forest categories were analysed with LMMs, except "Daily activity: Both”, ”Guild: Orb 829 web" and "Guild: Other hunters", whose equivariance hypotheses were not validated and for 830 which we performed GLMMs using Penalised Quasi-Likelihood (PQL).

831

832

833

834

835

836

837

838

839

840

841

842

843

844

845

846

847

848

849

850 
851

852

853

854

855

856

857

858

859

860

861

862

863

864

865

866

867

868

869

870

871

872

Step 3 : Statistical treatments

(e)

873

874

875

\section{Figures}

Figure 1

(a) Selection of species-by-sites dataset

Step 1 : Selection \& preparation of the dataset

Species-by-sites reference database (723 species / 218 sampling plots)

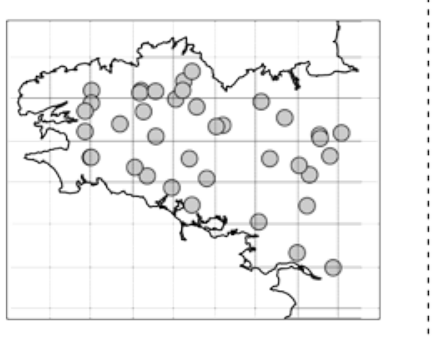

- Type of forests \& surface area

- Temporal forest continuity

- Sampling method

Species-by-sites dataset

(110 species / 56 plots (nested in 16 sites))

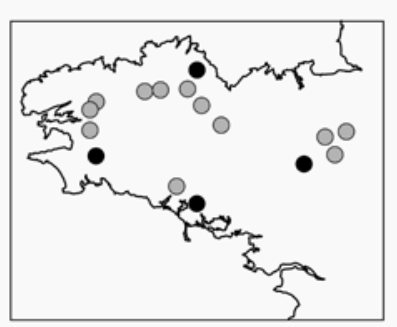

\section{Step 2 : Calculation of the indices}

(c) Composition \& structure

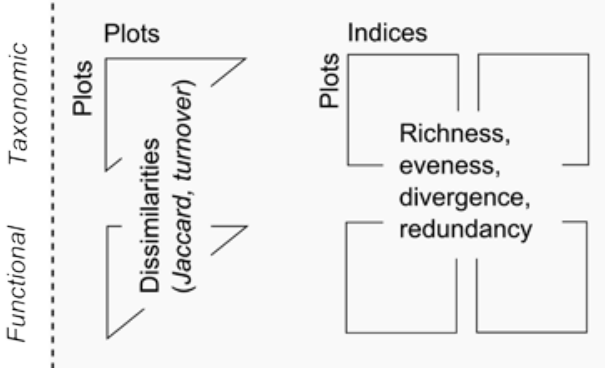

645 species whose traits are availabled

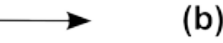

(b) Functional distance between species

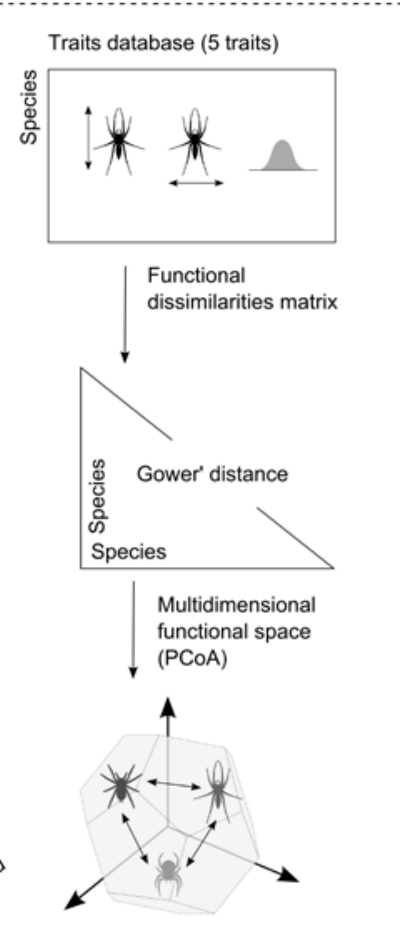

Functional coordinates and occurences of the 645 species

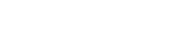

(d) Conservation importance

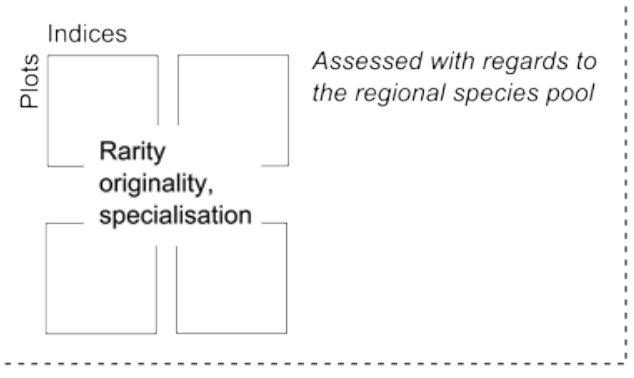

(G)LMMs

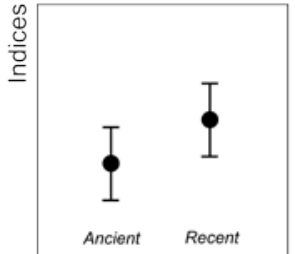


Page 34 on 51

$876 \quad$ Figure 2

877

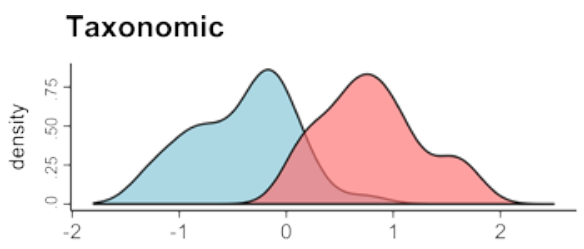

879
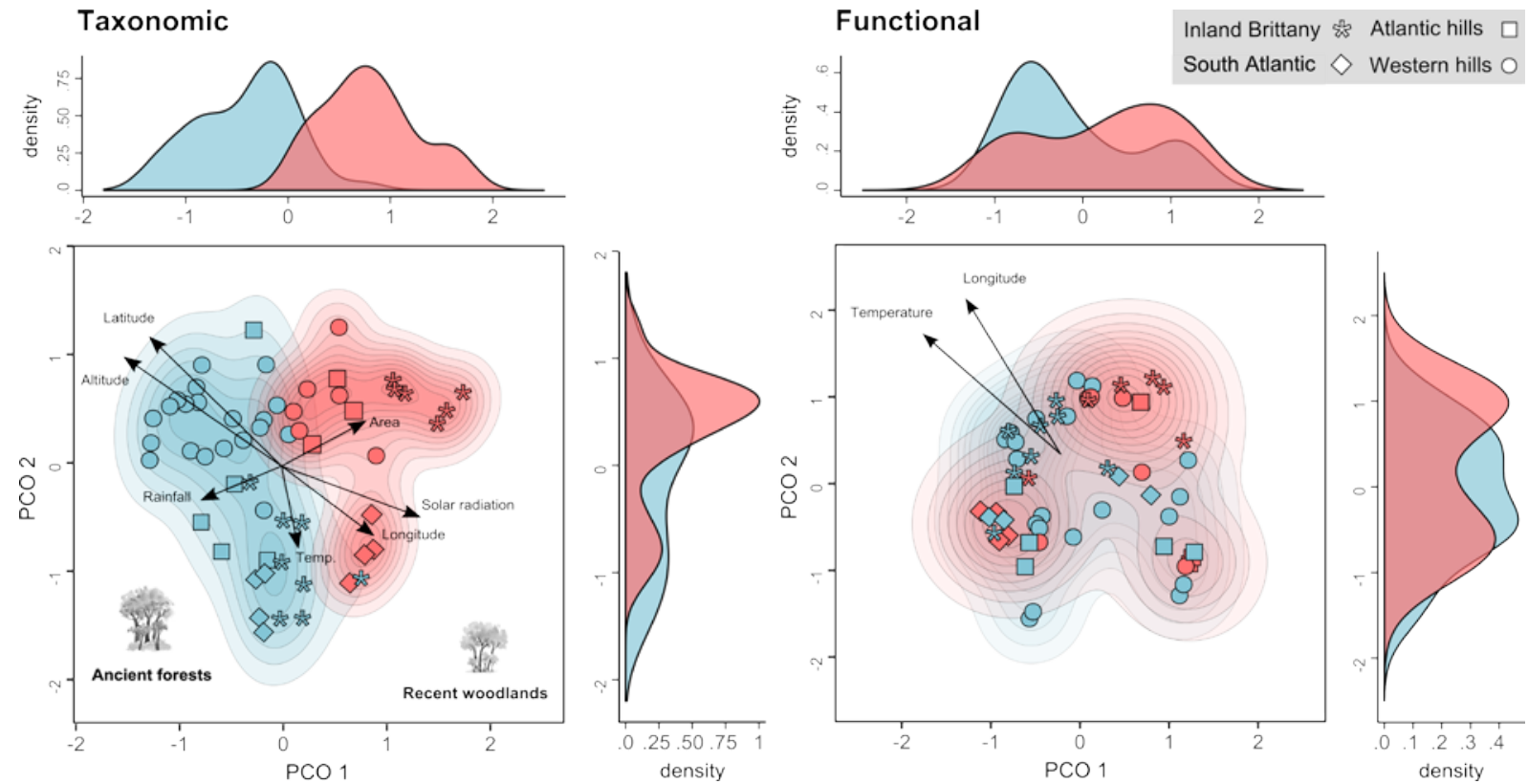

880

881

882

883

884

885

886

887

888

889

890

891

892

893

894

895

896

897

898

899

900

901

902 
Page $\mathbf{3 5}$ on $\mathbf{5 1}$

903

904

905

906

907

908

909

910

911

912

913

914

915

916

917

918

919

920

921

922

923

924

925

926

927

928

Figure 3

Taxonomic structure

(a)

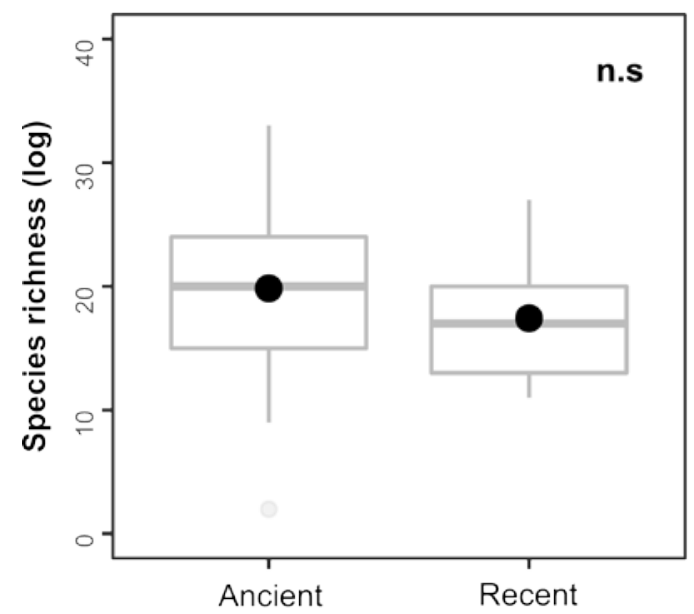

(c)

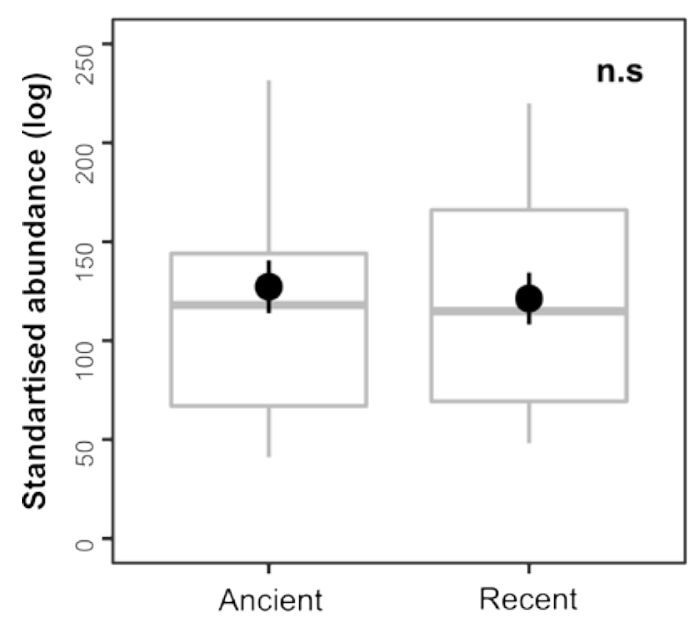

(e)

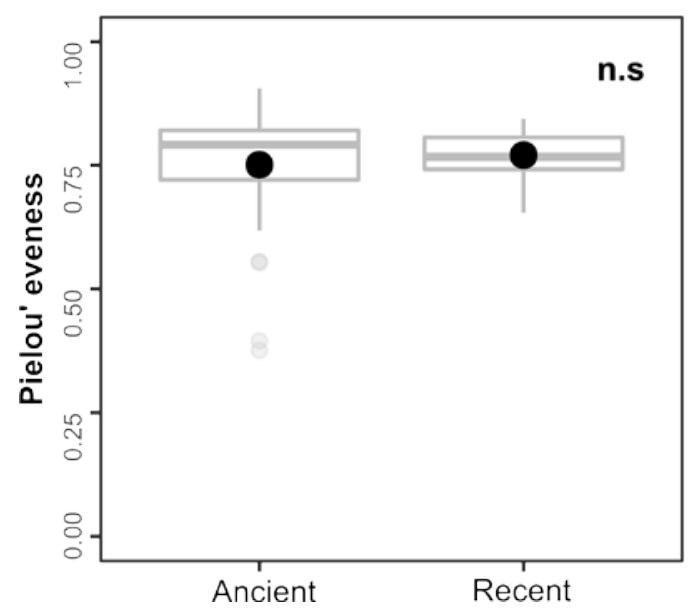

Functional structure

(b)

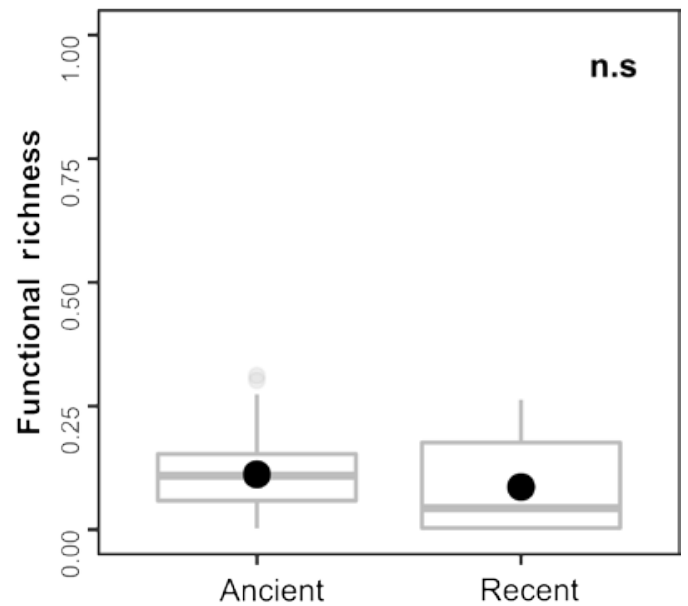

(d)

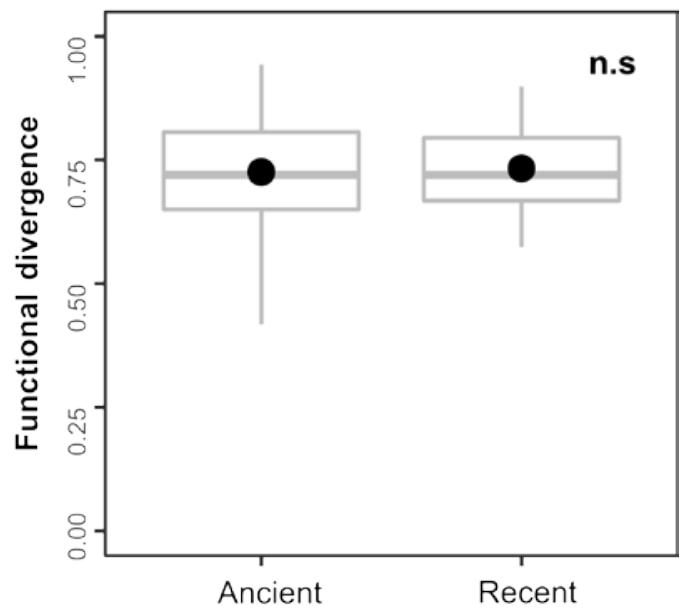

(f)

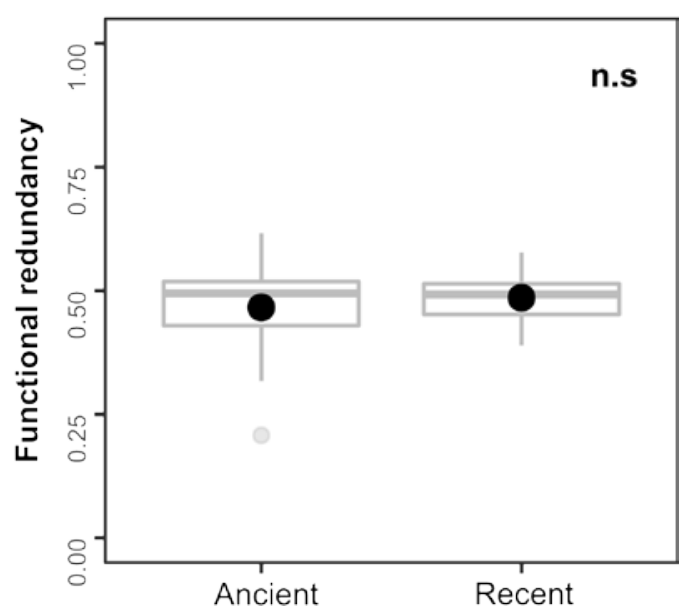




\section{Page 36 on 51}

$929 \quad$ Figure 4

930

(a)

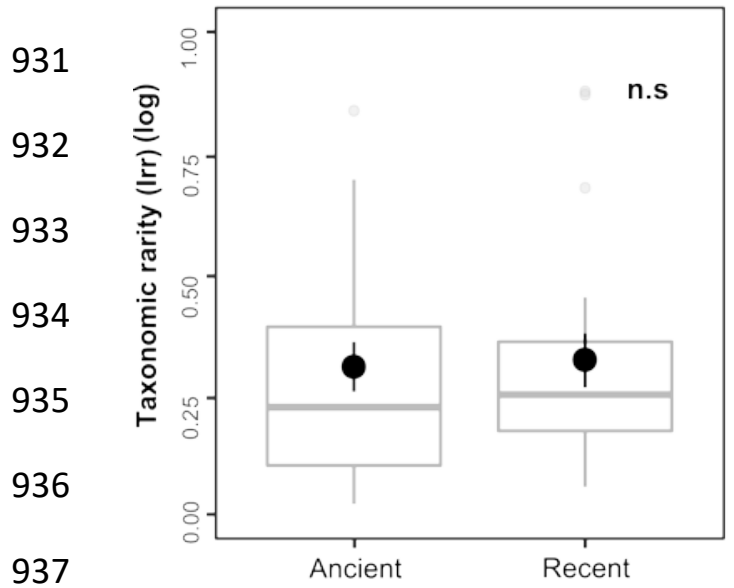

(c)

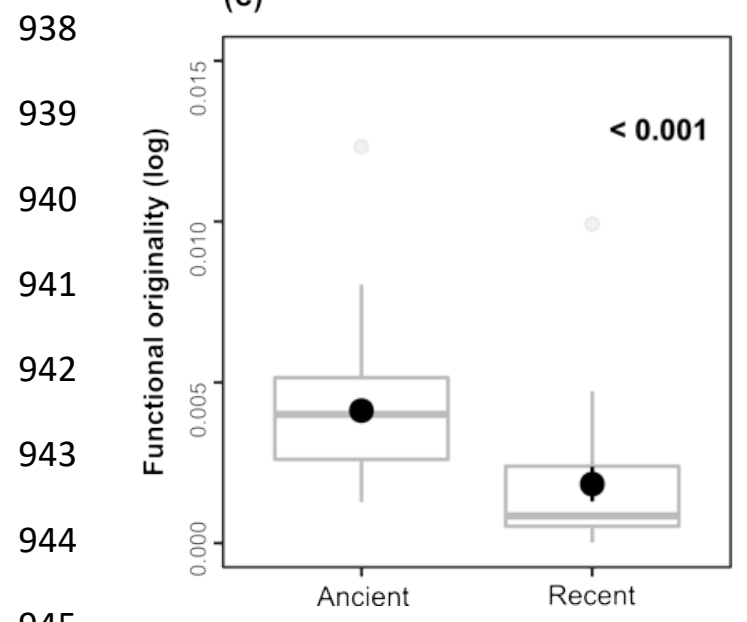

(b)

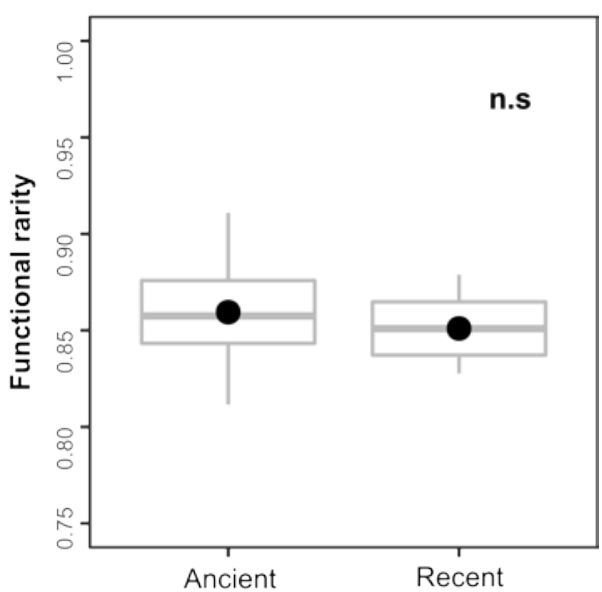

(d)

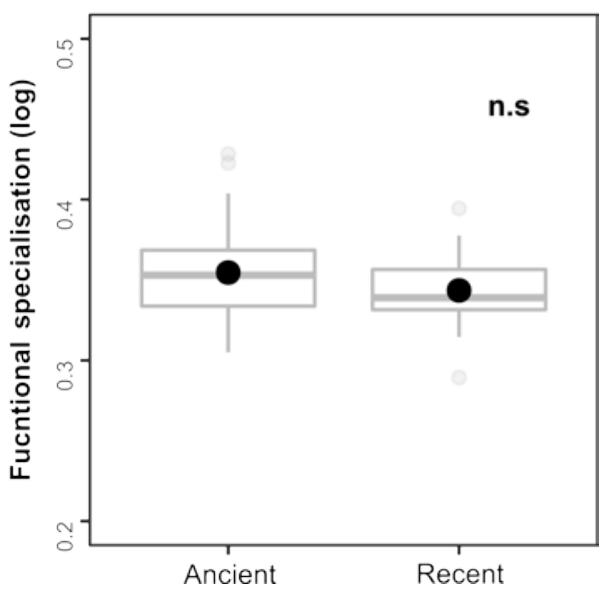

946

947

948

949

950

951

952

953

954

955 
Page $\mathbf{3 7}$ on $\mathbf{5 1}$

957

Figure 5

958

959

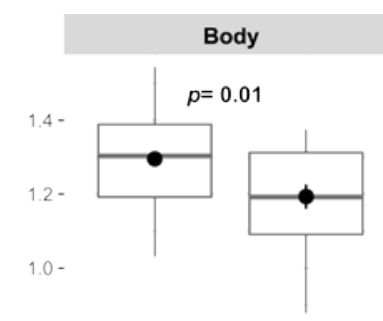

$$
\text { Ancient }
$$

Recent

Phenology: Summer

$p=0.2$

964

965

966

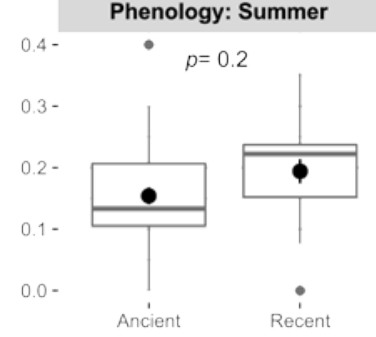

967

Guild: Ambush hunters

968

969

970

971

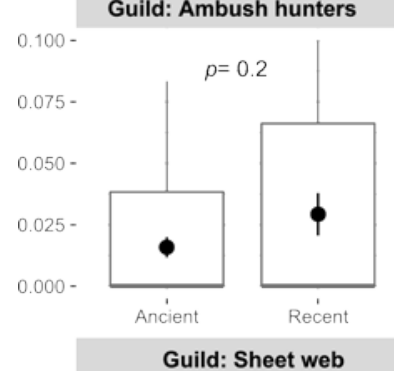

972

973

974

Guild: Sheet web

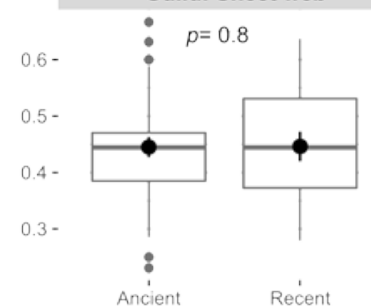

975 Stratum: Vegetation-dwellers

976

977

978

979

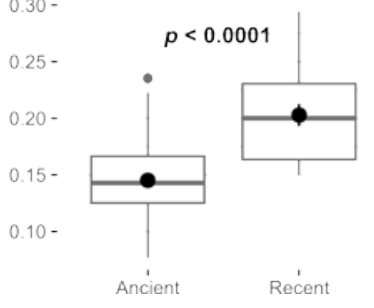

980

981

982

983 
Page 38 on $\mathbf{5 1}$

Tables

986

987

Table 1 Overview of the functional diversity indices used in the study at the $\alpha$-level. While

988

989

990

991

the first three indices analysed functional structure in each local community, FOri and FSpe were measured from the whole pool, i.e. the 645 species included in the functional space.

\begin{tabular}{llll} 
FD Component $\quad$ Index $\quad$ Measurement type & $\begin{array}{l}\text { Weighted } \\
\text { abundance }\end{array}$ & $\begin{array}{l}\text { Influence } \\
\text { of } \\
\text { richness }\end{array}$ \\
\hline
\end{tabular}

Local communities

\begin{tabular}{|c|c|c|c|}
\hline Functional richness & FRic & $\begin{array}{l}\text { the volume of multidimensional } \\
\text { space occupied by all species in a } \\
\text { community within a functional } \\
\text { space }\end{array}$ & No \\
\hline Functional divergence & FDiv & $\begin{array}{l}\text { the proportion of total abundance } \\
\text { supported by species with the most } \\
\text { extreme trait values within a } \\
\text { community }\end{array}$ & Yes \\
\hline Functional redundancy & FR & $\begin{array}{l}\text { difference between species diversity } \\
\text { and Rao's quadratic entropy based } \\
\text { on their functional dissimilarity }\end{array}$ & Yes \\
\hline
\end{tabular}

Whole regional pool

Functional

specialisation

Functional originality
FSpe

the mean distance of a species from

the rest of the species pool in a

functional space

the isolation of a species in the

FOri functional space occupied by a given community
Yes No

Yes

No 
Page 39 on 51

996

997

998

999

1000

1001

Table 2 Summary of taxonomic and functional pairwise dissimilarities (Jaccard's index and Jaccard-derived dissimilarities) (i) within overall plots, (ii) within ancient and recent forests, (iii) between ancient and recent forests, and contribution of the turnover to each combination of pairwise dissimilarities. Values are mean \pm standard deviation with confidence interval at $95 \%$ in brackets.

\begin{tabular}{ll}
\hline Taxonomic & Functional \\
\hline
\end{tabular}

Plot-to-plot variation

Overall forests $0.71 \pm 0.09[0.70-0.71]$ $0.79 \pm 0.17[0.78-0.80]$

Contribution of turnover

$0.61 \pm 0.13$ [0.61 - 0.62]

$0.44 \pm 0.27[0.43-0.46]$

Ancient forests

$0.68 \pm 0.09$ [0.68 - 0.69]

$0.76 \pm 0.19$ [0.74 - 0.77]

Contribution of turnover

$0.58 \pm 0.13$ [0.57 - 0.59]

$0.46 \pm 0.25$ [0.44 - 0.48]

Recent woodlands

$0.66 \pm 0.10$ [0.65 - 0.68]

$0.82 \pm 0.16[0.80-0.85]$

Contribution of turnover

$0.56 \pm 0.14$ [0.54 - 0.58]

$0.40 \pm 0.26[0.36-0.43]$

$\beta$-diversity between ancient and recent forests

Overall ancient vs. recent

$$
\begin{array}{ll}
0.74 \pm 0.8[0.73-0.74] & 0.81 \pm 0.16[0.80-0.82] \\
0.67 \pm 0.12[0.65-0.67] & 0.43 \pm 0.29[0.41-0.46]
\end{array}
$$

Contribution of turnover

1002

1003

1004

1005

1006

1007

1008

1009 
1011

1012

1013

1014

1015

Table 3 Pearson's correlation coefficients of the nine environmental variables based on PCoA ordination (see Fig. 2); $\mathrm{r}^{2}$ is the coefficient of determination and describes the goodness of fit, $p$ refers to the significance of the correlation between the gradient and the PCoA scores, based on a random permutation $(\mathrm{n}=9,999) .{ }^{*} p \leq 0.05 ; * * p \leq 0.01 ; * * * p \leq 0.001$.

\begin{tabular}{llll} 
Taxonomic & & Functional \\
$\mathrm{r}^{2} \quad p$ & & $\mathrm{r}^{2} \quad p$ \\
\hline
\end{tabular}

\section{Environmental variables}

\begin{tabular}{llllll} 
Altitude & 0.58 & $* * *$ & 0.01 & n.s. \\
Area of sites & 0.14 & $*$ & 0.11 & n.s. \\
Latitude & 0.54 & $* * *$ & 0.03 & n.s. \\
Longitude & 0.20 & $* *$ & 0.18 & $* *$ \\
Rainfall ${ }_{1997-2006}$ & 0.12 & $*$ & 0.02 & n.s. \\
Temperature maximum 2015 & 0.11 & n.s & 0.18 & $* *$ \\
Solar radiation ${ }_{1997-2006}$ & 0.34 & $* * *$ & 0.01 & n.s. \\
& & & & \\
Geological substrate & 0.14 & $* * *$ & 0.11 & n.s. \\
Temporal forest continuity & 0.35 & $* * *$ & 0.04 & n.s. \\
\hline
\end{tabular}

1016 
Page 41 on 51

1025

1026

1027

1028

1029

1030

1031

1032

1033

1034

1035

1036

1037

1038

1039

1040

1041

1042

1043

1044

1045

1046

1047

1048

1049

\section{SUPPLEMENTARY MATERIAL}

Authors: Loïs Morel ${ }^{1}$, Benoît Dujol ${ }^{1}$, Cyril Courtial ${ }^{1}$, Manon Vasseur ${ }^{1}$, Boris Leroy $^{2}$ and Frédéric Ysnel ${ }^{1}$

Title: Spontaneous recovery of functional diversity and rarity of ground-living spiders shed light on the conservation importance of recent woodlands

Affiliations: ${ }^{1}$ Géoarchitecture, Territoires, Urbanisation, Biodiversité et Environnement (GTUBE EA 7462) Université de Rennes 1, Université de Brest, Campus de Beaulieu, 35042 Rennes, France ; ${ }^{2}$ Unité Biologie des Organismes et Écosystèmes Aquatiques (BOREA UMR 7208), Sorbonne Universités, Muséum National d’Histoire Naturelle, Université de Caen Normandie, Université des Antilles, CNRS, IRD, 43 Rue Cuvier, CP26, 75005 Paris, France, boris.leroy@mnhn.fr

Corresponding author: Loïs MOREL, Université de Rennes 1, Campus de Beaulieu, Bâtiment 25, 1 er étage, 35042 Rennes cedex, E-mail: morellois@hotmail.com 
1054

1055

1056

1057

1058

1059

1060

1061

1062

1063

1064

1065

1066

1067

1068

1069

1070

1071

1072

1073

1074

1075 (a)

(b)

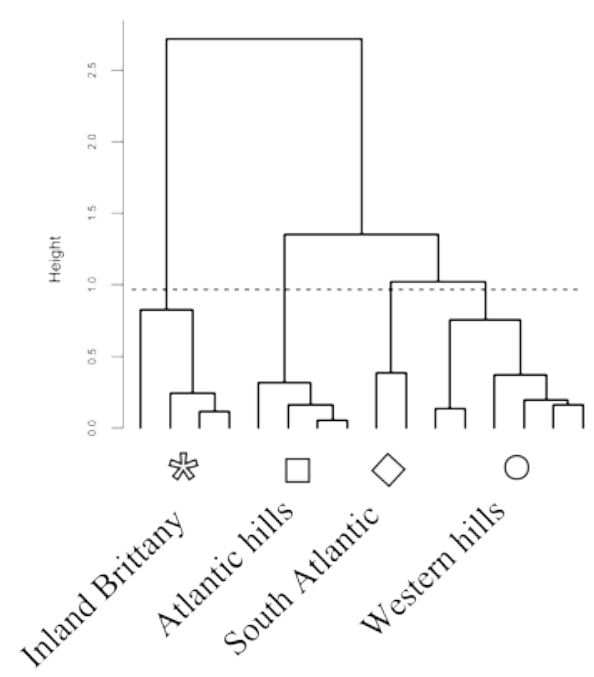

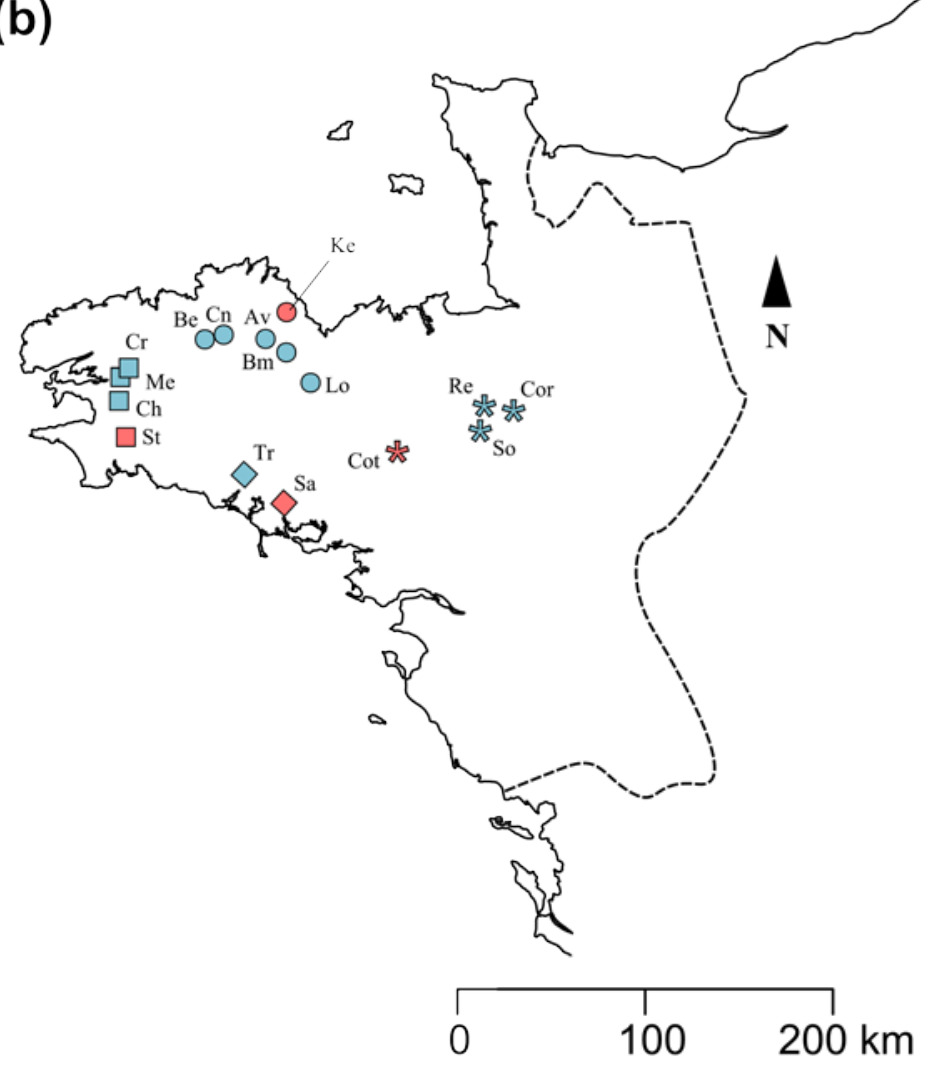


Page $\mathbf{4 3}$ on 51

1077 Summarised description of the forest sites according to the variables assessed at the site scale.

\begin{tabular}{|c|c|c|c|c|c|}
\hline Abbreviation & $\begin{array}{l}\text { No of } \\
\text { plots }\end{array}$ & $\begin{array}{l}\text { Geological } \\
\text { substrate }\end{array}$ & Area (ha) & Altitude (m) & Sampling year \\
\hline
\end{tabular}

Sites

\begin{tabular}{lllllll}
\hline Avaugour & Av & 6 & Granite rock & 1100 & 169 & 2013 \\
Beaumanoir & Bm & 3 & Volcanic rock & 300 & 214 & 2014 \\
Beffou & Be & 5 & Volcanic rock & 630 & 248 & 2014 \\
Bois du Chap & Ch & 2 & Sandstone & 40 & 91 & 2014 \\
Coat-an-noz & Cn & 3 & Volcanic rock & 1900 & 215 & 2014 \\
Coetquidan & Cot & 6 & Sandstone & 4000 & 97 & 2015 \\
Corbières & Cor & 3 & Sandstone & 630 & 101 & 2014 \\
Cranou & Cr & 2 & Sandstone & 1300 & 206 & 2014 \\
Kério & Ke & 6 & Volcanic rock & 200 & 94 & 2013 \\
Lorges & Lo & 3 & Schist & 2000 & 215 & 2014 \\
Menez & Me & 1 & Sandstone & 10 & 310 & 2014 \\
Rennes & Re & 3 & Schist & 3000 & 58 & 2014 \\
Sal & Sa & 4 & Granite rock & 52 & 32 & 2014 \\
Soeuvres & So & 2 & Schist & 115 & 54 & 2014 \\
Stangala & St & 3 & Granite rock & 57 & 59 & 2014 \\
Tremelin & Tr & 4 & Granite rock & 144 & 72 & 2014 \\
\hline
\end{tabular}

1078

1079

1080

1081

1082

1083

1084

1085 
Page 44 on 51

1086

1087

1088

1089

1090

1091

1092

1093

1094

1095

1096

1097

1098

1099

1100

1101

1102

1103

1104

1105

1106

1107

\section{Online Resource 2}

\section{Arthropod sampling}

In each plot, three pitfall traps consisting of polypropylene cups (10 cm diameter, $17 \mathrm{~cm}$ deep) with preservative solution (300 g.l $\mathrm{l}^{-1}$ of $\mathrm{NaCl}$ ) (Spence and Niemela 1994), were placed at the middle of the plots and spaced out $10 \mathrm{~m}$ apart along a 20-m transect. This distance was considered to be the minimum distance to avoid interference between traps (Topping and Sunderland 1992). Trap size and type were selected based on Lange et al. (2011) to optimise arthropod sampling and limit the risk of trapping vertebrates involuntarily.

The 168 traps (56 plots x 3 traps) were collected fortnightly from April to June of 2013, or 2014, or 2015, and stored in 70\% ethylalcohol. Only adults were considered for the studies.

Lange M, Gossner MM, Weissr WW (2011) Effect of pitfall trap type and diameter on vertebrate by-catches and ground beetle (Coleoptera: Carabidae) and spider (Araneae) sampling. Methods Ecol Evol 2: 185-190.

Spence JR, and Niemelä J (1994) Sampling carabid assemblages with pitfall traps: the madness and the method. Can Entomol 126: 881-894.

Topping CJ, Sunderland KD (1992) Limitations to the pitfall traps in ecological-sudies exemplified by a study of spiders in a field of winter-wheat. J Appl Ecol 29: 485-491. 
Online Resource 3

1110 Trait data used to describe the functional features of the 110 species recorded in the dataset.

\begin{tabular}{|c|c|c|c|c|c|c|}
\hline Family & Species & Body & Phenology & Daily activity & Hunting & Substrat \\
\hline \multirow[t]{3}{*}{ Agelenidae } & Coelotes terrestris & 13 & Spring & Nocturnal & Sheet web & Surface \\
\hline & Eratigena picta & 7 & Autumn-Winter & Both & Sheet web & Surface \\
\hline & Tegenaria silvestris & 7 & Eurychron & Both & Sheet web & Surface \\
\hline Amaurobiidae & Amaurobius similis & 12 & Eurychron & Nocturnal & Sheet web & Surface \\
\hline Atypidae & Atypus affinis & 15 & Eurychron & Both & Ambush hunters & Surface \\
\hline \multirow[t]{2}{*}{ Clubionidae } & Clubiona comta & 6 & Summer & Nocturnal & Other hunters & Vegetation \\
\hline & Clubiona terrestris & 7 & Eurychron & Nocturnal & Other hunters & Surface \\
\hline Dictynidae & Cicurina cicur & 7 & Eurychron & Both & Ground hunters & Surface \\
\hline \multirow[t]{3}{*}{ Dysderidae } & Dysdera erythrina & 10 & Eurychron & Nocturnal & Ground hunters & Surface \\
\hline & Dysdera fuscipes & 3.2 & Spring & Nocturnal & Ground hunters & Surface \\
\hline & Harpactea hombergi & 7 & Eurychron & Nocturnal & Ground hunters & Vegetation \\
\hline \multirow[t]{4}{*}{ Gnaphosidae } & Drassyllus lutetianus & 7.5 & Spring & Both & Ground hunters & Surface \\
\hline & Haplodrassus silvestris & 10 & Summer & Both & Ground hunters & Surface \\
\hline & Trachyzelotes pedestris & 8 & Summer & Both & Ground hunters & Surface \\
\hline & Zelotes apricorum & 9 & Summer & Both & Ground hunters & Surface \\
\hline \multirow[t]{3}{*}{ Hahniidae } & Hahnia helveola & 3 & Eurychron & Both & Sheet web & Surface \\
\hline & Hahnia ononidum & 2.5 & Autumn-Winter & Both & Sheet web & Surface \\
\hline & Iberina montana & 2 & Eurychron & Both & Sheet web & Surface \\
\hline \multirow[t]{23}{*}{ Linyphiidae } & Agyneta ramosa & 2.5 & Summer & Both & Sheet web & Surface \\
\hline & Bathyphantes gracilis & 2.5 & Eurychron & Both & Sheet web & Surface \\
\hline & Centromerus albidus & 1.5 & Eurychron & Both & Sheet web & Surface \\
\hline & Centromerus brevipalpus & 3 & Autumn-Winter & Both & Sheet web & Surface \\
\hline & Centromerus dilutus & 1.5 & Eurychron & Both & Sheet web & Surface \\
\hline & Centromerus serratus & 1.7 & Eurychron & Both & Sheet web & Surface \\
\hline & Centromerus sylvaticus & 4 & Eurychron & Both & Sheet web & Surface \\
\hline & Ceratinella scabrosa & 2.3 & Summer & Both & Wandering web & Surface \\
\hline & Dicymbium tibiale & 2.6 & Eurychron & Both & Wandering web & Surface \\
\hline & Diplocephalus cristatus & 2.5 & Eurychron & Both & Wandering web & Surface \\
\hline & Diplocephalus latifrons & 2 & Eurychron & Both & Wandering web & Surface \\
\hline & Diplocephalus picinus & 1 & Summer & Both & Wandering web & Surface \\
\hline & Diplostyla concolor & 3 & Eurychron & Both & Sheet web & Surface \\
\hline & Erigone atra & 2.8 & Eurychron & Both & Wandering web & Surface \\
\hline & Erigone dentipalpis & 2.6 & Eurychron & Both & Wandering web & Surface \\
\hline & Gonatium rubellum & 3.4 & Eurychron & Both & Wandering web & Surface \\
\hline & Gongylidiellum latebricola & 1.9 & Summer & Both & Wandering web & Surface \\
\hline & Gongylidiellum vivum & 1.9 & Eurychron & Both & Wandering web & Surface \\
\hline & Gongylidium rufipes & 3.7 & Summer & Both & Wandering web & Surface \\
\hline & Jacksonella falconeri & 1.2 & Eurychron & Both & Wandering web & Surface \\
\hline & Labulla thoracica & 6.4 & Eurychron & Both & Sheet web & Vegetation \\
\hline & Linyphia hortensis & 5 & Spring & Both & Sheet web & Vegetation \\
\hline & Macrargus rufus & 4.6 & Eurychron & Both & Sheet web & Surface \\
\hline
\end{tabular}




\begin{tabular}{|c|c|c|c|c|c|c|}
\hline & Maro minutus & 1.5 & Eurychron & Both & Sheet web & Surface \\
\hline & Maso sundevalli & 1.8 & Eurychron & Both & Wandering web & Vegetation \\
\hline & Micrargus apertus & 2.2 & Eurychron & Both & Wandering web & Surface \\
\hline & Micrargus herbigradus & 1.9 & Eurychron & Both & Wandering web & Surface \\
\hline & Microneta viaria & 3 & Eurychron & Both & Sheet web & Surface \\
\hline & Minyriolus pusillus & 1.3 & Spring & Both & Wandering web & Surface \\
\hline & Monocephalus fuscipes & 2.2 & Eurychron & Both & Wandering web & Surface \\
\hline & Neriene clathrata & 5 & Eurychron & Both & Sheet web & Vegetation \\
\hline & Oedothorax apicatus & 3.3 & Eurychron & Both & Wandering web & Surface \\
\hline & Oedothorax retusus & 3 & Eurychron & Both & Wandering web & Surface \\
\hline & Ostearius melanopygius & 2.6 & Eurychron & Both & Wandering web & Surface \\
\hline & Palliduphantes pallidus & 2.3 & Eurychron & Both & Sheet web & Vegetation \\
\hline & Parapelecopsis nemoralis & 2.1 & Eurychron & Both & Wandering web & Surface \\
\hline & Pocadicnemis pumila & 2.2 & Spring & Both & Wandering web & Surface \\
\hline & Saaristoa abnormis & 4 & Eurychron & Both & Sheet web & Surface \\
\hline & Saloca diceros & 1.4 & Autumn-Winter & Both & Sheet web & Surface \\
\hline & Sintula corniger & 2 & Eurychron & Both & Wandering web & Surface \\
\hline & Tapinocyba mitis & 1.5 & Autumn-Winter & Both & Wandering web & Surface \\
\hline & Tenuiphantes cristatus & 2.8 & Autumn-Winter & Both & Sheet web & Vegetation \\
\hline & Tenuiphantes flavipes & 2.5 & Eurychron & Both & Sheet web & Vegetation \\
\hline & Tenuiphantes tenuis & 3.2 & Eurychron & Both & Sheet web & Vegetation \\
\hline & Tenuiphantes zimmermanni & 3.2 & Eurychron & Both & Sheet web & Vegetation \\
\hline & Tiso vagans & 2.2 & Eurychron & Both & Wandering web & Surface \\
\hline & Trichoncus affinis & 2.5 & Eurychron & Both & Wandering web & Surface \\
\hline & Walckenaeria acuminata & 4 & Eurychron & Both & Wandering web & Surface \\
\hline & Walckenaeria atrotibialis & 2.8 & Summer & Both & Wandering web & Surface \\
\hline & Walckenaeria corniculans & 3 & Eurychron & Both & Wandering web & Surface \\
\hline & Walckenaeria cucullata & 2.7 & Eurychron & Both & Wandering web & Surface \\
\hline & Walckenaeria cuspidata & 2.9 & Eurychron & Both & Wandering web & Surface \\
\hline & Walckenaeria dysderoides & 2.2 & Spring & Both & Wandering web & Surface \\
\hline & Walckenaeria incisa & 3.2 & Eurychron & Both & Wandering web & Surface \\
\hline & Walckenaeria mitrata & 3.3 & Spring & Both & Wandering web & Surface \\
\hline & Walckenaeria nudipalpis & 2.7 & Eurychron & Both & Wandering web & Surface \\
\hline & Walckenaeria obtusa & 3.8 & Eurychron & Both & Wandering web & Surface \\
\hline & Wiehlea calcarifera & 1.3 & Eurychron & Both & Wandering web & Surface \\
\hline Liocranidae & Agroeca brunnea & 8 & Eurychron & Both & Ground hunters & Surface \\
\hline & Apostenus fuscus & 4 & Eurychron & Both & Ground hunters & Surface \\
\hline & Scotina celans & 4.7 & Eurychron & Both & Ground hunters & Surface \\
\hline Lycosidae & Alopecosa pulverulenta & 10 & Summer & Diurnal & Ground hunters & Surface \\
\hline & Hygrolycosa rubrofasciata & 6 & Spring & Diurnal & Ground hunters & Surface \\
\hline & Pardosa amentata & 8 & Summer & Diurnal & Ground hunters & Surface \\
\hline & Pardosa hortensis & 5.5 & Summer & Diurnal & Ground hunters & Surface \\
\hline & Pardosa prativaga & 6 & Summer & Diurnal & Ground hunters & Surface \\
\hline & Pardosa proxima & 6.5 & Summer & Diurnal & Ground hunters & Surface \\
\hline & Pardosa pullata & 6 & Eurychron & Diurnal & Ground hunters & Surface \\
\hline & Pardosa saltans & 5.7 & Summer & Diurnal & Ground hunters & Surface \\
\hline & Pirata uliginosus & 6 & Summer & Diurnal & Ground hunters & Surface \\
\hline
\end{tabular}




\section{Page 47 on 51}

\begin{tabular}{|c|c|c|c|c|c|c|}
\hline & Piratula hygrophila & 6.5 & Summer & Diurnal & Ground hunters & Surface \\
\hline & Piratula latitans & 5 & Summer & Diurnal & Ground hunters & Surface \\
\hline & Trochosa ruricola & 14 & Eurychron & Diurnal & Ground hunters & Surface \\
\hline & Trochosa terricola & 14 & Eurychron & Diurnal & Ground hunters & Surface \\
\hline Miturgidae & Zora spinimana & 6.5 & Eurychron & Both & Ground hunters & Surface \\
\hline Phrurolithidae & Phrurolithus festivus & 3 & Summer & Both & Ground hunters & Surface \\
\hline Salticidae & Neon reticulatus & 3 & Eurychron & Diurnal & Other hunters & Surface \\
\hline \multirow[t]{3}{*}{ Tetragnathidae } & Metellina mengei & 6 & Summer & Both & Orb web & Vegetation \\
\hline & Pachygnatha clercki & 7 & Eurychron & Both & Orb web & Surface \\
\hline & Pachygnatha degeeri & 3.7 & Eurychron & Both & Orb web & Surface \\
\hline \multirow[t]{6}{*}{ Theridiidae } & Enoplognatha thoracica & 4 & Eurychron & Both & Space web & Surface \\
\hline & Euryopis flavomaculata & 4 & Summer & Both & Space web & Surface \\
\hline & Pholcomma gibbum & 1.5 & Eurychron & Both & Space web & Surface \\
\hline & Robertus lividus & 4 & Eurychron & Both & Space web & Surface \\
\hline & Theonoe minutissima & 1.2 & Eurychron & Both & Space web & Surface \\
\hline & Theridion mystaceum & 2.5 & Summer & Both & Space web & Vegetation \\
\hline \multirow[t]{5}{*}{ Thomisidae } & Cozyptila blackwalli & 4 & Eurychron & Both & Ambush hunters & Surface \\
\hline & Ozyptila praticola & 4 & Eurychron & Both & Ambush hunters & Surface \\
\hline & Ozyptila trux & 5 & Eurychron & Both & Ambush hunters & Surface \\
\hline & Xysticus cristatus & 8 & Summer & Both & Ambush hunters & Vegetation \\
\hline & Xysticus luctator & 10 & Summer & Both & Ambush hunters & Surface \\
\hline Zodariidae & Zodarion italicum & 3 & Summer & Both & Ambush hunters & Surface \\
\hline
\end{tabular}

1111

1112

1113

1114

1115

1116

1117

1118

1119

1120

1121

1122

1123 
Page 48 on 51

1124

1125 Species richness, richness estimator and completeness of each site of the datasets. Completeness is the ratio between observed and estimated richness (Soberón et al., 2007). For each site, completeness was

1127 based on three estimators (Chao2, Jacknife 1 and ICE). For species richness and completeness values 1128 are means \pm standard errors.

\begin{tabular}{|c|c|c|c|c|c|c|c|}
\hline & $\begin{array}{l}\text { No of } \\
\text { plots }\end{array}$ & $\begin{array}{l}\text { Total } \\
\text { richness }\end{array}$ & $\begin{array}{l}\text { Mean species } \\
\text { richness } \pm \text { se }\end{array}$ & Chao2 & Jacknife 1 & ICE & $\begin{array}{l}\text { Completeness } \\
\text { index } \pm \text { se }\end{array}$ \\
\hline Overall datasets & 56 & 110 & $19.02 \pm 0.75$ & 0.80 & 0.91 & 0.79 & $0.83 \pm 0.04$ \\
\hline Recent woodlands & 19 & 71 & $17.42 \pm 1.12$ & 0.49 & 0.85 & 0.70 & $0.68 \pm 0.11$ \\
\hline Coetquidan & 6 & 32 & $16 \pm 1.15$ & 0.80 & 0.78 & 0.91 & $0.83 \pm 0.04$ \\
\hline Kério & 6 & 38 & $17.33 \pm 1.61$ & 0.73 & 0.73 & 0.87 & $0.78 \pm 0.05$ \\
\hline Sal & 4 & 41 & $23.75 \pm 1.97$ & 0.77 & 0.73 & 0.84 & $0.78 \pm 0.03$ \\
\hline Stangala & 3 & 21 & $12 \pm 0.58$ & 0.63 & 0.66 & 0.69 & $0.66 \pm 0.02$ \\
\hline Ancient forests & 37 & 101 & $19.84 \pm 0.95$ & 0.72 & 0.87 & 0.75 & $0.78 \pm 0.05$ \\
\hline Avaugour & 6 & 28 & $13.33 \pm 1.05$ & 0.86 & 0.78 & 0.90 & $0.85 \pm 0.04$ \\
\hline Beaumanoir & 3 & 29 & $19.67 \pm 0.88$ & 0.82 & 0.75 & 0.83 & $0.80 \pm 0.03$ \\
\hline Beffou & 5 & 45 & $21.8 \pm 1.88$ & 0.79 & 0.74 & 0.85 & $0.80 \pm 0.03$ \\
\hline Bois du Chap & 2 & 19 & - & - & - & - & - \\
\hline Coat-an-noz & 3 & 32 & $21.33 \pm 4.33$ & 0.69 & 0.71 & 0.80 & $0.74 \pm 0.03$ \\
\hline Corbières & 3 & 37 & $21.33 \pm 1.33$ & 0.72 & 0.68 & 0.72 & $0.70 \pm 0.01$ \\
\hline Cranou & 2 & 46 & - & - & - & - & - \\
\hline Lorges & 3 & 24 & $16 \pm 0.58$ & 0.78 & 0.73 & 0.81 & $0.77 \pm 0.02$ \\
\hline Menez & 1 & 13 & - & - & - & - & - \\
\hline Rennes & 3 & 49 & $28 \pm 2.65$ & 0.61 & 0.66 & 0.69 & $0.65 \pm 0.02$ \\
\hline Soeuvres & 2 & 33 & - & - & - & - & - \\
\hline Tremelin & 4 & 40 & $22 \pm 3.03$ & 0.87 & 0.76 & 0.85 & $0.83 \pm 0.04$ \\
\hline
\end{tabular}

\begin{tabular}{|c|c|c|c|c|c|c|c|}
\hline & $\begin{array}{l}\text { No of } \\
\text { plots }\end{array}$ & $\begin{array}{l}\text { Total } \\
\text { richness }\end{array}$ & $\begin{array}{l}\text { Mean species } \\
\text { richness } \pm \text { se }\end{array}$ & Chao2 & Jacknife 1 & ICE & $\begin{array}{l}\text { Completeness } \\
\text { index } \pm \text { se }\end{array}$ \\
\hline Overall datasets & 56 & 110 & $19.02 \pm 0.75$ & 0.80 & 0.91 & 0.79 & $0.83 \pm 0.04$ \\
\hline Recent woodlands & 19 & 71 & $17.42 \pm 1.12$ & 0.49 & 0.85 & 0.70 & $0.68 \pm 0.11$ \\
\hline Coetquidan & 6 & 32 & $16 \pm 1.15$ & 0.80 & 0.78 & 0.91 & $0.83 \pm 0.04$ \\
\hline Kério & 6 & 38 & $17.33 \pm 1.61$ & 0.73 & 0.73 & 0.87 & $0.78 \pm 0.05$ \\
\hline Sal & 4 & 41 & $23.75 \pm 1.97$ & 0.77 & 0.73 & 0.84 & $0.78 \pm 0.03$ \\
\hline Stangala & 3 & 21 & $12 \pm 0.58$ & 0.63 & 0.66 & 0.69 & $0.66 \pm 0.02$ \\
\hline Ancient forests & 37 & 101 & $19.84 \pm 0.95$ & 0.72 & 0.87 & 0.75 & $0.78 \pm 0.05$ \\
\hline Avaugour & 6 & 28 & $13.33 \pm 1.05$ & 0.86 & 0.78 & 0.90 & $0.85 \pm 0.04$ \\
\hline Beaumanoir & 3 & 29 & $19.67 \pm 0.88$ & 0.82 & 0.75 & 0.83 & $0.80 \pm 0.03$ \\
\hline Beffou & 5 & 45 & $21.8 \pm 1.88$ & 0.79 & 0.74 & 0.85 & $0.80 \pm 0.03$ \\
\hline Bois du Chap & 2 & 19 & - & - & - & - & - \\
\hline Coat-an-noz & 3 & 32 & $21.33 \pm 4.33$ & 0.69 & 0.71 & 0.80 & $0.74 \pm 0.03$ \\
\hline Corbières & 3 & 37 & $21.33 \pm 1.33$ & 0.72 & 0.68 & 0.72 & $0.70 \pm 0.01$ \\
\hline Cranou & 2 & 46 & - & - & - & - & - \\
\hline Lorges & 3 & 24 & $16 \pm 0.58$ & 0.78 & 0.73 & 0.81 & $0.77 \pm 0.02$ \\
\hline Menez & 1 & 13 & - & - & - & - & - \\
\hline Rennes & 3 & 49 & $28 \pm 2.65$ & 0.61 & 0.66 & 0.69 & $0.65 \pm 0.02$ \\
\hline Soeuvres & 2 & 33 & - & - & - & - & - \\
\hline Tremelin & 4 & 40 & $22 \pm 3.03$ & 0.87 & 0.76 & 0.85 & $0.83 \pm 0.04$ \\
\hline
\end{tabular}


1131 Summary of the statistical tests for all the indices used to analyse differences in structure, 1132 taxonomic and functional $\alpha$-diversity of spider communities of ancient forests and recent 1133 woodlands.

\begin{tabular}{|c|c|c|c|c|}
\hline Metrics & Ancient forests & Recent woodlands & Wald's test & $p$ \\
\hline Species richness & $19.8 \pm 0.95$ & $17.4 \pm 1.11$ & 1.4 & 0.24 \\
\hline Standardised abundance (log) & $127.2 \pm 13.4$ & $121.3 \pm 13.1$ & 0.04 & 0.85 \\
\hline Pielou’ eveness & $0.75 \pm 0.02$ & $0.77 \pm 0.02$ & 0.6 & 0.44 \\
\hline FRic & $0.12 \pm 0.01$ & $0.08 \pm 0.02$ & 3.12 & 0.08 \\
\hline FDiv & $0.72 \pm 0.02$ & $0.74 \pm 0.02$ & 0.11 & 0.73 \\
\hline FR & $0.46 \pm 0.01$ & $0.47 \pm 0.01$ & 0.19 & 0.66 \\
\hline$I_{R R}(\log )$ & $0.30 \pm 0.05$ & $0.32 \pm 0.06$ & 0.16 & 0.69 \\
\hline FRar & $0.86 \pm 0.004$ & $0.85 \pm 0.004$ & 1.43 & 0.23 \\
\hline FOri (log) & $0.007 \pm 0.001$ & $0.004 \pm 0.001$ & 12.9 & 0.0003 \\
\hline FSpe & $0.36 \pm 0.01$ & $0.36 \pm 0.01$ & 0.4 & 0.53 \\
\hline $\mathrm{CWM}_{\text {Body }}$ & $1.3 \pm 0.2$ & $1.19 \pm 0.03$ & 6.7 & 0.01 \\
\hline CWM Phenology: Autumn/Winter & $0.08 \pm 0.01$ & $0.03 \pm 0.01$ & 11.4 & 0.0007 \\
\hline CWM Phenology: Eurychron & $0.73 \pm 0.01$ & $0.74 \pm 0.02$ & 1.06 & 0.30 \\
\hline CWM Phenology: Spring & $0.03 \pm 0.01$ & $0.03 \pm 0.01$ & 0.01 & 0.92 \\
\hline CWM Phenology: Summer & $0.15 \pm 0.01$ & $0.19 \pm 0.02$ & 1.56 & 0.21 \\
\hline CWM Daily activity: Both & $0.82 \pm 0.01$ & $0.88 \pm 0.02$ & 3.74 & 0.05 \\
\hline CWM Daily activity: Diurnal & $0.09 \pm 0.01$ & $0.07 \pm 0.01$ & 1.21 & 0.27 \\
\hline CWM Daily activity: Nocturnal & $0.09 \pm 0.01$ & $0.05 \pm 0.01$ & 1.32 & 0.25 \\
\hline CWM Guild: Ambush hunters & $0.16 \pm 0.004$ & $0.03 \pm 0.01$ & 1.39 & 0.24 \\
\hline CWM Guild: Ground hunters & $0.19 \pm 0.01$ & $0.15 \pm 0.02$ & 3.63 & 0.056 \\
\hline CWM Guild: Orb web & $0.005 \pm 0.002$ & $0.01 \pm 0.01$ & 4.34 & 0.03 \\
\hline CWM Guild: Others hunters & $0.03 \pm 0.01$ & $0.01 \pm 0.01$ & 4.75 & 0.03 \\
\hline CWM Guild: Sheet web & $0.45 \pm 0.02$ & $0.45 \pm 0.03$ & 0.09 & 0.76 \\
\hline CWM Guild: Space web & $0.04 \pm 0.01$ & $0.07 \pm 0.01$ & 8.94 & 0.003 \\
\hline CWM Guild: Wandering web & $0.28 \pm 0.02$ & $0.28 \pm 0.01$ & 0.01 & 0.92 \\
\hline CWM Stratum: Ground-dwellers & $0.85 \pm 0.01$ & $0.8 \pm 0.01$ & 16.9 & $<0.0001$ \\
\hline CWM Stratum: Vegetation-dwellers & $0.16 \pm 0.01$ & $0.2 \pm 0.01$ & 16.9 & $<0.0001$ \\
\hline
\end{tabular}


Page $\mathbf{5 0}$ on $\mathbf{5 1}$

1135

1136

113

1138

1139

1140

1141

1142

1143

1144

1145

1146

1147

1148

1149

1150

1151

1152

1153

1154

1155

1156

1157

1158

\section{Online Resource 6}

Shepard diagrams showing the goodness of fit of the measured pairwise dissimilarities of the spider assemblages as compared to the pairwise dissimilarities represented by PCoA ordination, for the taxonomic level (a) and the functional level (b).

(a)

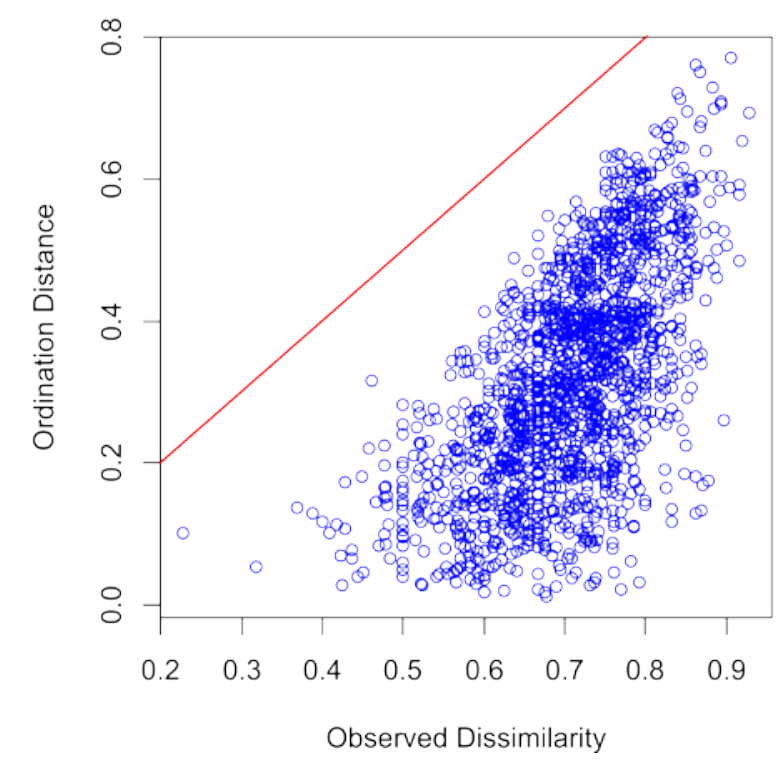

(b)

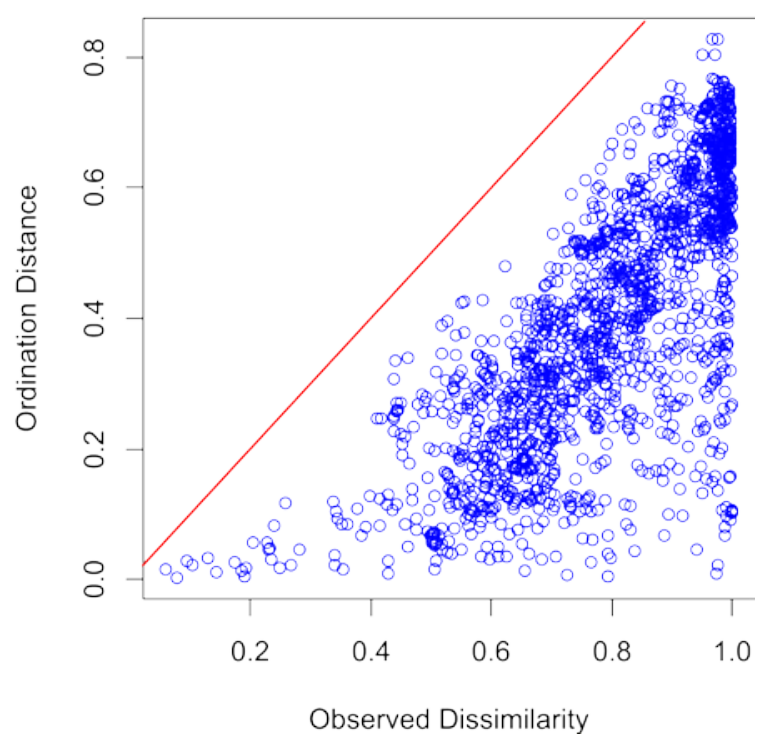




\section{Page 51 on 51}

1159

1160

1161

1162

1163

1164

1165

1166

1167

1168

1169

1170

1171

1172

1173

1174

1175

1176

1177

1178

1179

1180

1181

1182

1183

1184

Online Resource 7

Table representing the distribution of the 110 spider species between ancient forests and recent woodlands with their weight of functional originality (a) and specialisation (b) assessed from the functional space (see Table 1 for details of metrics). Coloured circles represent abundance standardised based on the number of days a trap was active. Grey circles represent the frequency of the species in each forest category (e.g. 0.25 for ancient forests, i.e. one species observed in 9/37 plots).

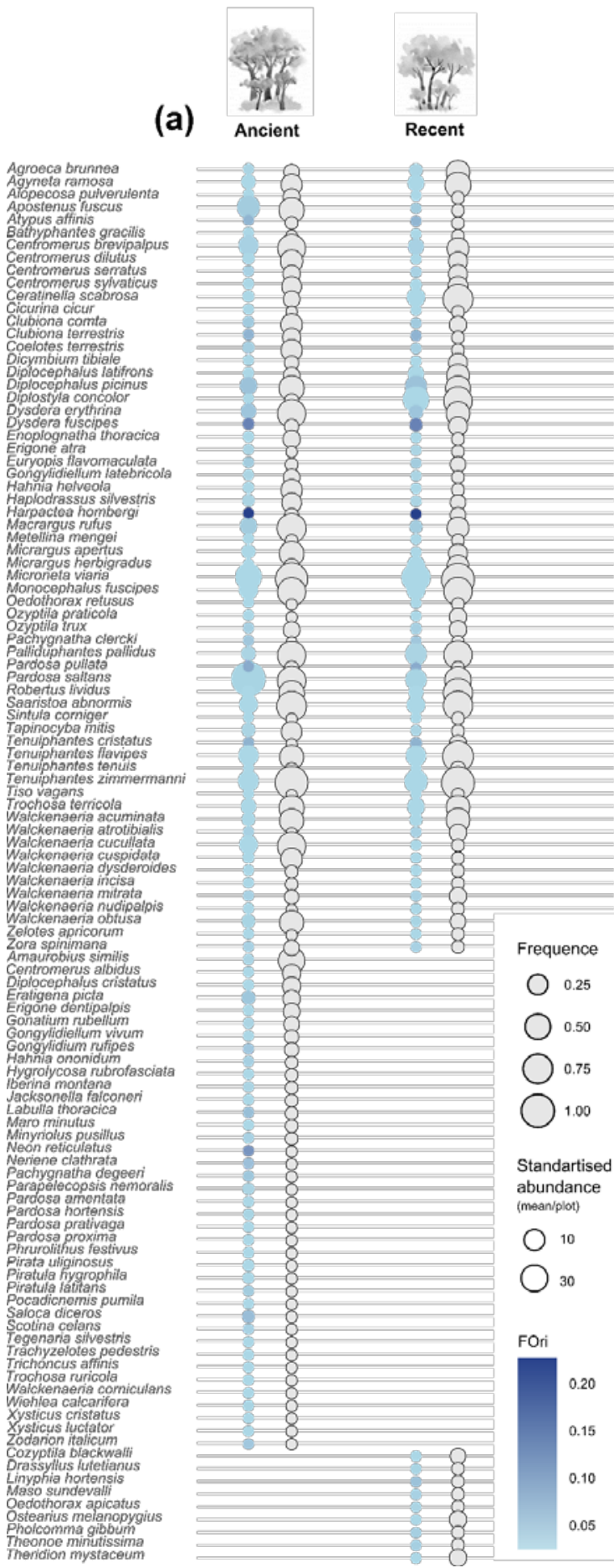

(b)
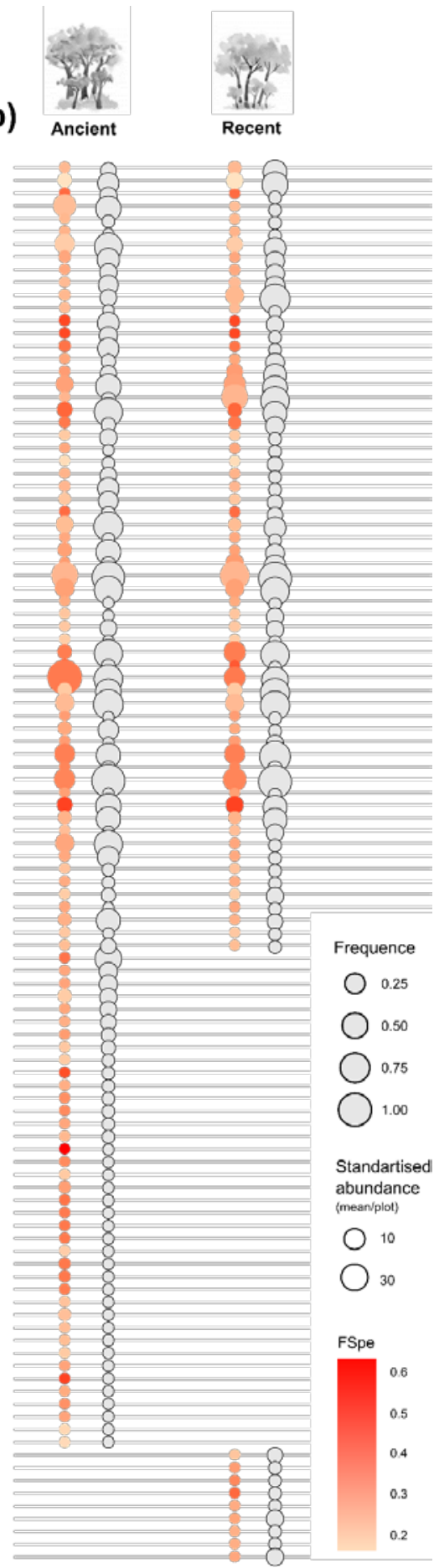